\title{
Transition metals in plant photosynthesis
}

Cite this: DOI: $10.1039 / \mathrm{c3mt00086a}$

Received 22nd March 2013,

Accepted 20th May 2013

DOI: $10.1039 / \mathrm{c} 3 \mathrm{mt} 00086 \mathrm{a}$

www.rsc.org/metallomics

\author{
Inmaculada Yruela*
}

Transition metals are involved in essential biological processes in plants since they are cofactors of metalloproteins and also act as regulator elements. Particularly, plant chloroplasts are organelles with high transition metal ion demand because metalloproteins are involved in the photosynthetic electron transport chain. The transition metal requirement of photosynthetic organisms greatly exceeds that of non-photosynthetic organisms, and either metal deficiency or metal excess strongly impacts photosynthetic functions. In chloroplasts, the transition metal ion requirement needs a homeostasis network that strictly regulates metal uptake, chelation, trafficking and storage since under some conditions metals cause toxicity. This review gives an overview of the current understanding of main features concerning the role of copper ( $\mathrm{Cu}$ ), iron (Fe), manganese $(\mathrm{Mn})$ and zinc ( $\mathrm{Zn})$ in plant photosynthesis as well as the mechanisms involved in their homeostasis within chloroplasts. The metalloproteins functioning in photosynthetic proteins of plants as well as those proteins participating in the metal transport and metal binding assembly are reviewed. Furthermore, the role of nickel ( $\mathrm{Ni}$ ) in artificial photosynthesis will be discussed.

\section{Introduction}

In general, transition metal ions are distinguished by their different chemical properties, which determine redox potential,

Estación Experimental de Aula Dei, Consejo Superior de Investigaciones Cientificas (EEAD-CSIC), Avda. Montañana, 1005, 50059 Zaragoza, Spain.

E-mail: i.yruela@csic.es; Fax: +34976716145

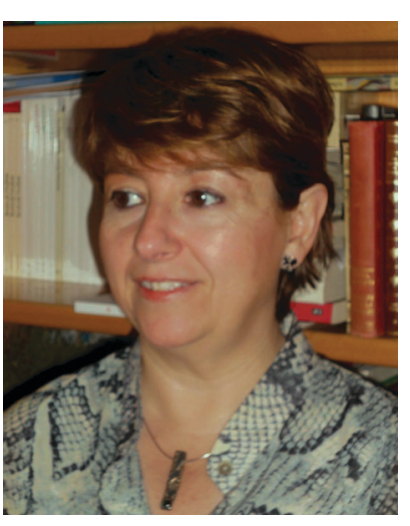

Inmaculada Yruela
Inmaculada Yruela earned her PhD (1989) in Chemistry at the University of Sevilla (Spain). Following a post-doctoral fellowship at the Max-Planck Institute for Bioinorganic Chemistry in Mülheim an der Ruhr (Germany), Inmaculada began her current position as a senior scientist at the Spanish Research Council, in the Estación Experimental de Aula Dei (EEAD-CSIC) in Zaragoza (Spain). Her research focuses on the structure and function of metalloproteins involved in the photosynthetic electron transport, the evolution of chloroplastic FAD synthetases, and more recently in the evolutionary dynamics of intrinsic disordered proteins in plants. coordination geometry, charge, thermodynamic and kinetic properties of ligand exchange, and consequently their specific functions. In a given metalloprotein the function is inseparable from the metal cofactor properties. ${ }^{1,2}$ In general the properties of metals, and in particular of transition metal ions bound to proteins, make them adequate candidates for electron transfer or for the transport of small molecular species. ${ }^{3}$ The electron transport can take advantage to finely tune the redox potential of the metal centre by the protein environment among others.

Chloroplasts contain diverse metalloproteins that function in photosynthetic electron transport reactions where their redox potentials are crucial for a specific function (i.e., cytochromes, ferredoxin, Fe-S proteins, plastocyanin). In some cases the transition metal is part of the active site for a catalytic process; in others the transition metal plays a role in maintaining the protein structure. The transition metal cofactor(s) can be (i) coordinated only by residues from the protein (i.e., carbonic anhydrase, plastocyanin); (ii) associated with other inorganic ions in a stable "cluster" that is bound to specific functional groups in the protein through the metal (i.e., ferredoxin, $\mathrm{F}_{\mathrm{X}}$ of PSI, Mn-cluster of PSII); (iii) form a stable (tetrapyrrole)chelated metal centre (i.e., cytochromes). ${ }^{4}$ Metals (Lewis acids) bind to functional groups (Lewis bases) according to preferences determined by the theory of acids and bases, which states that hard acids bind to hard bases and soft acids to soft bases. Thus, $\mathrm{Mn}^{2+}$ and $\mathrm{Fe}^{3+}$ are generally found bound to oxygen ligands (carboxylates, phenolates, carbonates, and phosphates), while $\mathrm{Cu}^{2+}, \mathrm{Fe}^{2+}, \mathrm{Ni}^{2+}$ and $\mathrm{Zn}^{2+}$ have an affinity for imidazolyl nitrogen, 
and $\mathrm{Cu}^{+}$has strong affinity for sulphur ligands (thiols, thiolates, thioethers). ${ }^{5,6}$ In redox proteins the configuration of the metal binding site is optimized for the changes in the metal oxidation state during the electron transport (i.e., $\mathrm{Fe}^{2+} / \mathrm{Fe}^{3+}$ or $\mathrm{Cu}^{+} / \mathrm{Cu}^{2+}$ or $\mathrm{S}_{i}$-states of Mn-cluster of PSII). In other cases, the metal binding stabilizes the structural folding of the protein (i.e., $\mathrm{Zn}^{2+}$ in $\mathrm{Cu} / \mathrm{Zn}$-superoxide dismutase). In some metalloproteins, such as the cytochrome, the metal cofactor is an essential determinant of the structure, while in others, such as plastocyanin and carbonic anhydrase, the metal binding site is preformed in the apoprotein. In other cases the incorporation of the metal is coupled with changes in the redox state of the metal or apoprotein, which serves to "trap" the metal within the complex (i.e., assembly of the Mn-cluster of PSII). Chloroplasts are particularly rich in $\mathrm{Fe}-\mathrm{S}$ proteins. The $\mathrm{Fe}-\mathrm{S}$ clusters are normally bound to proteins via sulfhydryl groups of cysteine (Cys) chains, although histidine (His), arginine (Arg) and glutamic acid (Glu) residues can also be involved. The most common $\mathrm{Fe}-\mathrm{S}$ clusters are $[2 \mathrm{Fe}-2 \mathrm{~S}]$ and $[4 \mathrm{Fe}-4 \mathrm{~S}]$ coordinated by four Cys, and a Rieske [2Fe-2S] cluster coordinated by two Cys and two His residues. All of them are characterized by their redox and catalytic properties. ${ }^{7}$

Other aspect to taking into account is that the availability of transition metals has determined the use of specific metalloproteins by organisms. For instance, when the earth's atmosphere favoured a higher availability of $\mathrm{Fe}^{2+}$ than that of $\mathrm{Cu}^{2+}$ many cyanobacteria and algae used cytochrome $c 6$ rather than plastocyanin (Pc). ${ }^{8}$ At present, such organisms depending on the presence of $\mathrm{Fe}$ and $\mathrm{Cu}$ in the growth medium balance the use of these two proteins, which function as electron carriers in photosynthetic electron transport. This scenario does not occur in higher plants where Pc is present and there is no evidence for cytochrome $c 6$, which has lost its primitive function. ${ }^{9}$ Another example that illustrates the changes in metal availability concerns to $\mathrm{Mn}$. In earlier geological times, changes in earth's reductant conditions allow oxygenic photosynthesis to be thermodynamically favourable due to the presence of an appropriate Mn complex, which could store oxidizing equivalents to produce the oxidation of two water molecules to dioxygen $\left(\mathrm{O}_{2}\right)$. It has been suggested that this could derive from a natural early marine $\mathrm{Mn}$ precipitate. ${ }^{10}$

The assembly of chloroplast metalloproteins requires the coordination of several biochemical processes such as metal transport, cofactor synthesis, modification of the apo-protein, insertion into the structural enzyme, and cofactor-protein association. The involvement of additional proteins such as chaperones, zinc-finger proteins, or posttranslational modification of an amino acid is required in some cases. For this machinery metal uptake, chelation, trafficking and storage have to be tightly regulated to maintain cellular metal concentrations within physiological limits. ${ }^{11-14}$

During the last twenty-five years a broad investigation has been done concerning oxygenic photosynthesis. In particular, many studies have been focused to investigate the structures of the membrane protein complexes and the soluble redox proteins that are involved in photosynthetic electron transport as well as to understand their functional mechanism and its regulation. More recently, the factors that modulate the electron transport, in part influenced by the availability of metals, or the importance of protein dynamics and cofactor interactions in controlling electron transport in oxygenic photosynthesis have also been of interest. These factors include hydrogen bonding, $\pi$-stacking and electrostatic interactions. For that analytical, biochemical, biophysical and molecular biology studies have been carried out in cyanobacteria, algae and plants yielding relevant functional and structural results. ${ }^{8,15-25}$ Additionally, in the last ten years advances in the understanding of transition metal homeostasis have been done. ${ }^{12,13}$ The goal of this review is to give an overview of the main structural features concerning the role of the transition metals, copper $(\mathrm{Cu})$, iron $(\mathrm{Fe})$, manganese (Mn) and zinc ( $\mathrm{Zn})$, in plant photosynthesis, with emphasis on the implications in their functionality. Moreover the recent investigations on transition metal transport and transition metal binding assembly within chloroplasts are reported. The role of transition metals in the field of artificial photosynthesis is also discussed.

\section{Copper}

Copper $(\mathrm{Cu})$ is a $3 \mathrm{~d}^{10}$ element essential for all organisms. The biological role for $\mathrm{Cu}$ started with the appearance of oxygen in earth's atmosphere, which changed from anaerobic to aerobic as oxygenic photosynthetic organisms evolved. In higher plants $\mathrm{Cu}$ availability is a prerequisite for growth and development. $\mathrm{Cu}$ content of soils ranges from 2 to $100 \mathrm{ppm}$, with an average value of about $30 \mathrm{ppm}$, but most of this is in unavailable mineral form. $\mathrm{Cu}$ is a redox-active transition metal that can exist as $\mathrm{Cu}^{2+}$ and $\mathrm{Cu}^{+}$under physiological conditions and act as a metal cofactor in certain metalloproteins involved in electron transport and oxidative stress response. In chloroplasts, it is a constituent of plastocyanin ( $\mathrm{Pc})$, the most abundant $\mathrm{Cu}$-protein in plant chloroplasts, which acts as an electron carrier in primary photosynthetic reactions. $\mathrm{Cu}$ is also a constituent of $\mathrm{Cu} / \mathrm{Zn}$-superoxide dismutase ( $\mathrm{Cu} / \mathrm{Zn}$-SOD), localized in the stroma that protects against reactive oxygen species (ROS) generated during the oxidative stress derived from the oxygenic photosynthetic reactions. ${ }^{13}$ The cation $\mathrm{Cu}^{2+}$ is often bound by nitrogen in histidine (His) side chains, whereas $\mathrm{Cu}^{+}$interacts with the sulphur in cysteine (Cys) and methionine (Met). $\mathrm{Cu}$ deficiency affects young leaves causing chlorosis and the reduction of photosynthetic activity. On the other hand, $\mathrm{Cu}$ in excess can become toxic causing among other symptoms the impairment of the photosynthetic activity. ${ }^{13}$ Thus, $\mathrm{Cu}$ homeostasis must be precisely coordinated and regulated.

\section{Plastocyanin}

Plastocyanin $(\mathrm{Pc})$ is a soluble protein, which localizes in the thylakoid lumen of chloroplasts and mediates the photosynthetic electron transport between two membrane protein complexes: cytochrome $b_{6} f$ (cyt $b_{6} f$ ) and photosystem I (PSI) (Fig. 1). The Pc contains a $\mathrm{Cu}^{2+}$ ion which is reduced by cyt $b_{6} f$ and subsequently the reduced $\mathrm{Cu}^{+}$ion can transfer one electron 


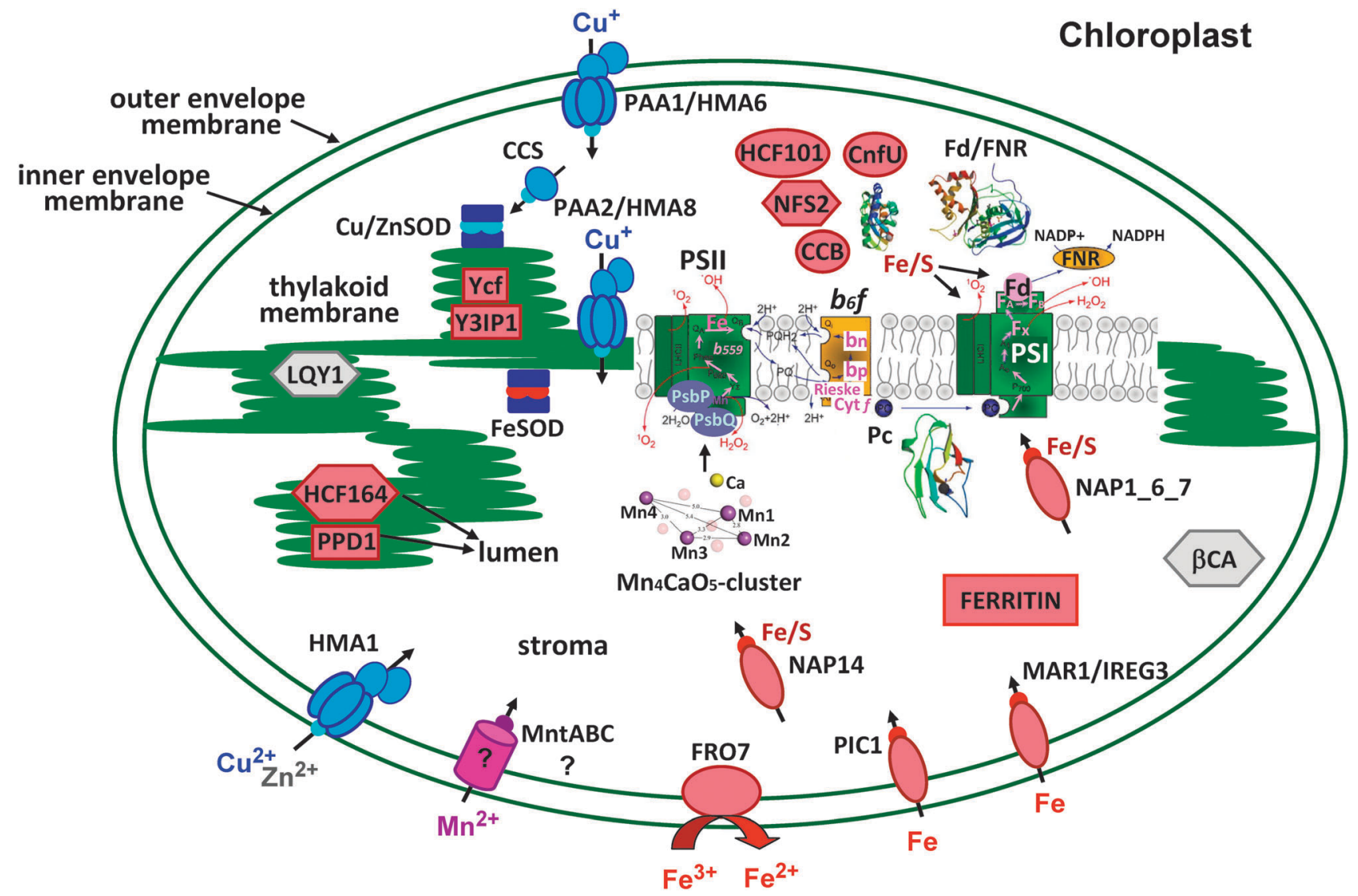

Fig. 1 Scheme of metal homeostasis and metalloproteins involved in photosynthesis within the chloroplast. Proteins associated with Cu (blue), Fe (dark pink), Mn (violet) and Zn (light grey) are differentiated by colours. Arrows indicate the proposed direction for metal transport. 3D structures from Fd-FNR complex (pdb 1FNB), $\mathrm{Pc}$ (pdb 1AG6), $\mathrm{Mn}_{4} \mathrm{CaO}_{5}$ (pdb 4IL6) and CnfU (pdb 2Z51) are shown. Transporters are represented with their putative metal. Fe cofactors in PSII, PSI and cyt $b_{6} f$ complex are labelled in pink. Proteins involved in Fe/S cluster insertion are represented by boxes. Scaffold proteins are represented by circles. Enzymes are represented by truncated boxes. CA, carbonic anhydrase; CCB, cofactor assembly on complex C subunit B; CCS, copper chaperone for Cu/Zn superoxide dismutase; CnfU, NifU-like protein; Cyt, cytochrome; Fd, ferredoxin; FNR, ferredoxin:NADP(H) reductase; FRO, ferric reductase oxidase; HCF, High Chlorophyll Fluorescence; HMA, heavy metal P-type ATPase; MAR1/IREG3, multiple antibiotic resistance1/iron-regulated protein3; NAP, non-intrinsic ABC protein; NFS, Nifs-like cysteine desulfurase; PAA, P-type ATPase of Arabidopsis; Pc, plastocyanin; PIC, permease in chloroplasts; PPD, PsbP-domain protein; SOD, superoxide dismutase; Ycf, Hypothetical Chloroplast Reading Frame; Y3IP, Ycf3-Interacting Protein. Scheme modified from, Shcolnick and Keren, ${ }^{54}$ Yruela, ${ }^{13}$ and Nouet et al. ${ }^{14}$

to the PSI. It is characterized by a midpoint high potential $\left(E_{\mathrm{m}} \approx+370 \mathrm{mV}\right.$ at $\left.\mathrm{pH} 7\right)$ and a relatively small relaxation energy connected to the redox process. This feature could be attributed to the rigid protein environment as a result of the six $\beta$-sheets of the protein structure. The active site is located in an easily accessible peripheral region of the protein that induces a constrained geometry on the $\mathrm{Cu}^{2+}$ ion. ${ }^{26}$

The Pc apo-protein is nuclear encoded and synthesized as a high molecular weight precursor in the cytoplasm. The newly synthesized Pc precursor is then post-translationally imported into the chloroplast. It is transported across three membranes into the thylakoid lumen. ${ }^{27} \mathrm{Pc}$ is a monomeric protein, with a molecular weight of around $10.5 \mathrm{kDa}$ and 99 amino acids in most vascular plants. Processing to the mature size involves successive cleavages by a stromal and a thylakoidal peptidase. When $\mathrm{Cu}$ supply is limited, higher plants prioritize the Cu delivery to Pc by down-regulation of other $\mathrm{Cu}$ proteins such as $\mathrm{Cu} / \mathrm{Zn}-\mathrm{SOD}^{28}$ Arabidopsis has two Pc isoforms, PETE1 and PETE2, which respond differently to $\mathrm{Cu}$ availability. ${ }^{28,29}$ PETE2 is the most abundant isoform and functions as a $\mathrm{Cu}$ buffering system under $\mathrm{Cu}$ stress. In addition to this role it acts as an electron carrier. PETE1 is not affected by $\mathrm{Cu}$ feeding and it is the isoform that drives electron transport under Cu-deficiency. Plants with mutations in the Pc genes had altered $\mathrm{Cu}$ homeostasis.

The rapid turnover of Pc between cyt $b_{6} f$ complex and PSI enables the efficient use of light energy. The heme molecules in the cytochrome $f$ (cyt $f$ ) subunit of cyt $b_{6} f$ complex donate electrons to the $\mathrm{Cu}$ ions in $\mathrm{Pc}$, and the chlorophyll molecules, $\mathrm{P}_{700}$, in the PsaA and PsaB subunits of PSI accept electrons from Pc. The Pc rapidly cycles through the following steps: binding to cyt $b_{6} f$, accepting an electron from cyt $b_{6} f$, dissociating from cyt $b_{6} f$, binding to PSI, donating an electron to the photoexcited PSI, and then dissociating from PSI. The formation of such rapidly associating and dissociating electron transfer complexes facilitates efficient electron transport. ${ }^{30-32}$

The X-ray 3D structure of the isolated Pc has been determined from Spinacia oleracea, spinach (pdb 1YLB, 1AG6), Silene (pdb 1BYO) and Populus nigra, poplar, (pdb 4DP0). ${ }^{33-36} \mathrm{Pc}$ was 
the first of the blue $\mathrm{Cu}$ proteins to be characterised by X-ray crystallography.

In $\mathrm{Pc}$, the $\mathrm{Cu}^{2+} / \mathrm{Cu}^{+}$ion resides in the so-called type I Cu-centre, characterized by the presence of one Cys residue (Cys84) and two His residues (His37 and His38) strongly bound to $\mathrm{Cu}$ in a trigonal plane. A weakly bound methionine sulphur atom (Met92) completes the distorted coordination geometry of the metal ion. It has been suggested that such coordination is $\mathrm{pH}$-dependent and that this fact could serve as a regulatory switch for photosynthesis. ${ }^{37}$ The protein backbone is rigid displaying a small degree of mobility on the sub-nanosecond time scale. In contrast to the situation for other electron transfer proteins, no significant difference in the dynamic properties is found between the two redox forms. ${ }^{38}$

Electrons are transferred through the $\mathrm{Cu}$-ligand His87, situated in the middle of the hydrophobic patch, to $\mathrm{P}_{700}$ of PSI. Mutational analyses in $\mathrm{Pc}$ from spinach have revealed that the hydrophobic residues surrounding the $\mathrm{Cu}^{2+} / \mathrm{Cu}^{+}$ion, such as Leu12 and Ala90 and the acidic residues located adjacent to the hydrophobic patch, such as Asp42, Glu43, Asp44, Glu45, Glu59, Glu60, and Asp61 are important for Pc-PSI electron transport in eukaryotic plants ${ }^{39-44}$ and Pc-cyt $b_{6} f .^{32,40,45,46}$ The hydrophobic patch residues of Pc are in close proximity to PSI and cyt $b_{6} f$ complex, whereas the acidic patch residues of Pc do not form stable salt bridges with either PSI or cyt $b_{6} f$ complex, in the electron transfer complexes. ${ }^{47}$ The transient characteristics of the interactions on the acidic patch facilitate the rapid association and dissociation of Pc.

In plants, an additional interaction which involves acidic patches is necessary for electron transport. ${ }^{48}$ The rate of electron donation in vitro from Pc to PSI depends strongly on the concentration of divalent cations such as $\mathrm{Ca}^{2+}$ and $\mathrm{Mg}^{2+}$. Several evidence suggest that negatively charged residues in these patches form salt bridges with positively charged residues on the PSI subunit PsaF, further strengthening the binding to PSI. Studies in vitro using 2D NMR spectroscopy have suggested that a specific interaction of $\mathrm{Mg}^{2+}$ ions could regulate the binding of Pc to the subunit PsaF of PSI in vivo. ${ }^{48}$

In leaves from Populus (poplar) two Pc isoforms, PCa and $\mathrm{PCb}$, have been found which exhibit closely similar overall and active-site structures, except for a difference in the relative orientation of the acidic patches. The isoforms exhibit substantial differences in the dependence of the reduced $\left(\mathrm{Cu}^{+}\right)$geometry on $\mathrm{pH}$. In $\mathrm{PCa}$, the decrease in $\mathrm{pH}$ causes a gradual dissociation of His87 from $\mathrm{Cu}^{+}$at low $\mathrm{pH}$, probably adopting a neutral tautomeric state. In $\mathrm{PCb}$, the His residue remains covalently bound to $\mathrm{Cu}^{+}$and may adopt a doubly protonated state at low $\mathrm{pH}$. The fact that both isoforms have similar although not identical functions in photosynthetic electron flows suggests that the His87 imidazole does not play a crucial role in the pathway of electron transport from cyt $f$ to oxidized Pc. ${ }^{36}$

\section{Cu transport pathways in chloroplast}

Several families of proteins are involved in metal transport within the chloroplast, which include either integral membrane proteins or chaperones (soluble proteins). Two members of the $\mathrm{P}_{1 \mathrm{~B}}$-type ATPase family are involved in this $\mathrm{Cu}$ transport. Homologous proteins exist in bacteria and other eukaryotes (i.e. yeast, mammals). ${ }^{12,13,49}$ In Arabidopsis thaliana the subsequent action of PAA2/AtHMA8, a thylakoid located $\mathrm{Cu}$ transporter, and PAA1/AtHMA6, which is located in the inner chloroplast envelope, supplies $\mathrm{Cu}$ to $\mathrm{Pc}$ (Fig. 1). These $\mathrm{P}_{1 \mathrm{~B}}$-type ATPases transport monovalent $\mathrm{Cu}^{+}$ions across membranes following the classical E1/E2 Albers-Post catalytical cycle. ${ }^{49}$ The mechanism operating during metal delivery to metal transmembrane binding sites is still not clear but the requirement of conserved amino acid residues in the transmembrane region has been proposed. ${ }^{50,51}$ This finding has been observed in homologue proteins from bacteria. In plants there is no structural data on this kind of protein transporter. $\mathrm{Cu}$ levels control PAA2/AtHMA8 stability and Pc is a major determinant of this regulatory mechanism. ${ }^{52}$ This uptake system is functionally conserved from cyanobacteria to higher plants. ${ }^{53,54}$ Another P-type ATPase, HMA1, might also be involved in chloroplast $\mathrm{Cu}$ import. AtHMA1 localizes in the chloroplast envelope and affects $\mathrm{Zn}$ and $\mathrm{Cu}$ uptake when expressed in yeast (Fig. 1). ${ }^{55}$ AtHMA1 transport divalent $\mathrm{Cu}^{+2}$ ions rather that $\mathrm{Cu}^{+}$ions. Studies in Hordeum vulgare (barley) indicate that HvHMA1 is a broad-specificity exporter of metals from chloroplasts and serve as a scavenging mechanism for mobilizing $\mathrm{Cu}$ and $\mathrm{Zn}$ from plastids when cells become deficient in these elements. ${ }^{56,57}$

In cyanobacteria, two cytosolic ATX1-like proteins deliver $\mathrm{Cu}$ to a PAA2/AtHMA8 homolog, but no homologue metallochaperone has been localized into the chloroplast or described that interacts with PAA1/AtHMA1 or PPA2/AtHMA2. ${ }^{14}$ However, it is known that the chaperone that delivers $\mathrm{Cu}$ to the $\mathrm{Cu} / \mathrm{Zn}-\mathrm{SOD}$, the CCS protein, is localized in both cytosolic and plastidial compartments. ${ }^{13,58}$

\section{Iron}

Iron (Fe) is a $3 d^{6}$ element and the most common transition metal in living organisms. It is a redox-active metal that is able to exist as $\mathrm{Fe}^{2+}$ and $\mathrm{Fe}^{3+}$ under physiological conditions. Plants can uptake $\mathrm{Fe}$ in both oxidized forms but, although most of the Fe on the earth crust is in the form of $\mathrm{Fe}^{3+}$, the $\mathrm{Fe}^{2+}$ form is physiologically more significant for plants. Fe is present in high quantities in soils but its availability to plants is usually very low (especially in alkaline and calcareous soils), and therefore Fe deficiency is a common problem, which causes the reduction of photosynthetic activity. Chloroplasts represent the organelle with the highest requirement of Fe in plant cells. Up to $80 \%$ of the cellular Fe in leaf cells is found in chloroplasts. Fe is stored in the plastids in the form of ferritin, where it is mineralized with phosphate. ${ }^{59}$ Plastid-localized ferritin represents the central component for balancing Fe homeostasis in this organelle. The abundance of ferritin in the plastid is high in etioplasts and decreases dramatically during plastid development when synthesis of most of the FeS-containing metalloproteins is occurring. It becomes almost undetectable in the chloroplasts of the mature leaves. Thus, ferritins were hypothesized to be potential Fe donors in the build-up of a functional photosynthetic apparatus where Fe is mostly present as $\mathrm{Fe}-\mathrm{S}$ clusters. Interestingly, the chloroplast functionality does not depend on the presence of ferritin since in the Arabidopsis fer1-3-4 mutant PSII efficiency was not affected. ${ }^{60}$ 


\section{Photosystem I}

In chloroplasts, the chlorophyll-binding membrane protein complex PSI has a high requirement for Fe. The PSI from plants is a multi-protein complex formed by a reaction centre and lightharvesting complexes that is embedded in the thylakoid membrane of chloroplasts (Fig. 1). Its assembly requires an intricate coordination of gene expression and intensive communication between the two compartments since it is composed of subunits encoded in both the chloroplast genome and the nuclear genome. It generates the most negative redox potential in nature.

The X-ray 3D structure of PSI from Pisum sativum (pea) has been determined (pdb 1QZV, 2O01, 2WSC, 3LW5 $)^{61-63}$ and the composition of the PSI core and the function of its subunits have been extensively discussed and reviewed. ${ }^{64-67}$ While the PSI-core remained highly conserved throughout the evolution, with the exception of the oxidizing side of PSI, the LHCI complex shows a high degree of variability in size, subunit composition and bound pigments. $^{68-70}$ Each PSI monomer is composed of three [4Fe-4S] clusters, named $F_{A}, F_{B}$ and $F_{X}$, which drive the electrons from the site of initial charge separation to a soluble electron transfer protein, a [2Fe-2S] ferredoxin (Fig. 1 and 2). $\mathrm{F}_{\mathrm{A}}, \mathrm{F}_{\mathrm{B}}$, and $\mathrm{F}_{\mathrm{X}}$ are plastid-encoded, and their assembly occurs in the organelle. $\mathrm{F}_{\mathrm{A}}$ and $\mathrm{F}_{\mathrm{B}}$ are bound to the PsaC subunit and $\mathrm{F}_{\mathrm{X}}$ is an unusual

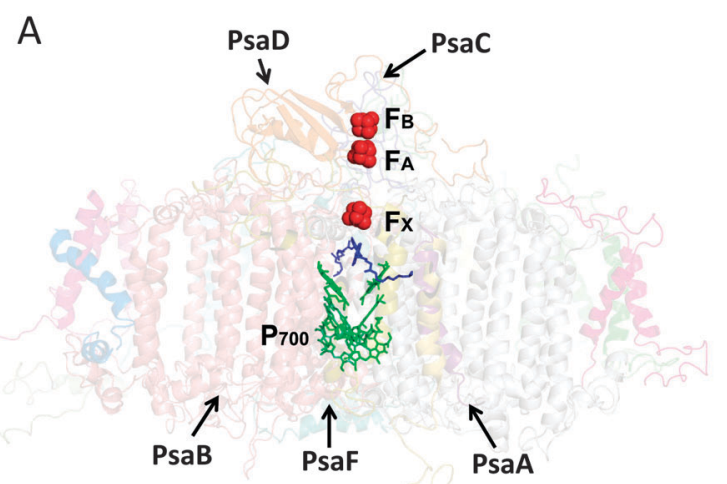

B

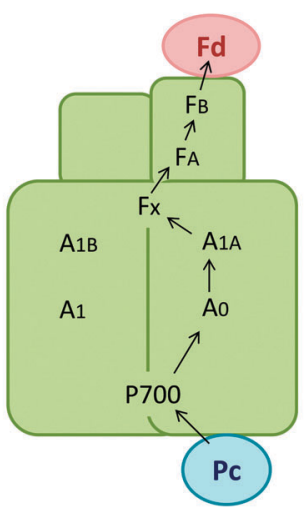

Fig. 2 (A) Ribbon diagram of the plant PSI from Pisum sativum, pea ( $p d b$ 2001). ${ }^{62}$ The cofactors involved in the PSI electron transport are shown: chlorophylls $a, P_{700}, A_{0}, A_{1}$ (green), phylloquinones, $A_{1 A}$ and $A_{1 B}$ (blue), and the ironsulphur clusters $F_{X}, F_{A}$ and $F_{B}(r e d)$. Chlorophylls and phylloquinones are shown as sticks. The iron-sulphur clusters are shown as spheres. (B) Diagram of electron transport pathway through PSI. Pc, plastocyanin; Fd, ferredoxin. interpolypeptide $[4 \mathrm{Fe}-4 \mathrm{~S}]$ cluster that bridges the PsaA/PsaB integral membrane polypeptides constituting the reaction centre heterodimer. $\mathrm{F}_{\mathrm{X}}$ is ligated by two Cys residues provided by PsaA and two Cys residues provided by PsaB in conserved loops. The two Cys in both proteins are proximal and located in a loop between the ninth and tenth transmembrane segments. This type of coordination of an $[4 \mathrm{Fe}-4 \mathrm{~S}]$ cluster is unique as it comprises two symmetry-equivalents and conserved segments belonging to two different subunits. The incorporation of the $[4 \mathrm{Fe}-4 \mathrm{~S}]$ cluster $\mathrm{F}_{\mathrm{X}}$ into the PsaA/PsaB heterodimer occurs after membrane insertion and heterodimer assembly and is itself a prerequisite for the subsequent binding of PsaC, which first binds its two [4Fe-4S] clusters in the stroma. Then, the holoprotein is incorporated into the stromal side of the PsaAB heterodimer and the binding to PsaAB triggers conformational changes in PsaC. These changes are further promoted by binding of PsaD, which stabilizes the association of PsaC with the heterodimer. ${ }^{71}$ The formation of the stromal ridge is finally completed by the stable binding of PsaE.

The PsaA and PsaB protein subunits bind two branches of electron-transport cofactors that catalyse the light-induced primary charge separation at the chlorophyll $a$ special pair $\mathrm{P}_{700}$, a chlorophyll $a$ /chlorophyll $a$ dimer, on the lumenal side of the thylakoid membrane, followed by a rapid electron transfer via the monomeric chlorophyll $a$ molecules, $\mathrm{A}_{0}$ and $\mathrm{A}_{1}$, the phylloquinones $\mathrm{A}_{1 \mathrm{~A}}$ and $\mathrm{A}_{1 \mathrm{~B}}$ (bound to PsaA and PsaB, respectively), and the [4Fe-4S] cluster $F_{X}$ localized on the stromal side to the final two [4Fe-4S] clusters, $\mathrm{F}_{\mathrm{A}}$ and $\mathrm{F}_{\mathrm{B}}{ }^{18,69}$ (Fig. 2). Based on site-directed mutagenesis, there is a general agreement that both branches are active at ambient temperature but that the majority of electrontransport events occur in the A-branch. Results from electron paramagnetic resonance (EPR) showed that the orientations of both phylloquinone radicals are different which affect the strength of hydrogen bonding between phylloquinone and the protein backbone. Both molecules have been suggested to be active during electron transfer reactions but with slightly different kinetics. ${ }^{72,73}$ Spectroscopic and biochemical techniques in combination with the classical Marcus theory for electron transfer tunnelling indicated a bi-directional kinetic model for electron transfer reactions in PSI. ${ }^{74,75}$ This model takes into consideration the thermodynamic equilibrium between $F_{X}$ and the phylloquinones $\mathrm{A}_{1 \mathrm{~A}}$ and $\mathrm{A}_{1 \mathrm{~B}}$, and the equilibrium between the $\mathrm{F}_{\mathrm{A}}$ and $\mathrm{F}_{\mathrm{B}}$ centres. The midpoint potential of the three $[4 \mathrm{Fe}-4 \mathrm{~S}]$ clusters, $\mathrm{F}_{\mathrm{X}}, \mathrm{F}_{\mathrm{A}}$, and $\mathrm{F}_{\mathrm{B}}$ ranges from $E_{\mathrm{m}} \approx+400 \mathrm{mV}$ to $E_{\mathrm{m}} \approx-705 \mathrm{mV}$. The reduction potential for $F_{X}$ measured by low temperature EPR spectroscopy was of $E_{\mathrm{m}} \approx-705 \pm 15 \mathrm{mV}$. The protein interactions make $F_{X}$ as one of the most electronegative iron-sulphur clusters. The midpoint potentials measured for $\mathrm{F}_{\mathrm{A}}$ and $\mathrm{F}_{\mathrm{B}}$ were found to be $E_{\mathrm{m}} \approx-540 \mathrm{mV}$ and $E_{\mathrm{m}} \approx-590 \mathrm{mV}$, respectively. ${ }^{16}$

The Fe-S clusters represent rather poor chromophores for optical spectroscopic studies because the $\mathrm{S} \rightarrow$ Fe chargetransfer bands are weak and broad due to variability in the ground state energy. EPR techniques have allowed us to detect and resolve signals from the individual Fe-S clusters. ${ }^{16,76}$ The EPR spectral properties of $\mathrm{F}_{\mathrm{X}}$ cofactor are unusual compared with other clusters. The average of the $g$-values $\left(g_{x x}=2.06, g_{y y}=1.86\right.$ and $\left.g_{z z}=1.76\right)^{77}$ is lower than in typical low-potential [4Fe-4S] 
clusters and the line widths are much broader as compared to $\mathrm{F}_{\mathrm{A}}$ and $\mathrm{F}_{\mathrm{B}}$. High-time-resolution EPR has also provided insights into electron transport pathways through both branches (A and $\mathrm{B}$ ) of PSI revealing different orientations of $\mathrm{A}_{1 \mathrm{~A}}{ }^{-}$and $\mathrm{A}_{1 \mathrm{~B}}{ }^{-}$in their respective binding sites. The formation of a strong hydrogen bond from $\mathrm{A}_{1}{ }^{-}$to the protein backbone is possible only in the case of $\mathrm{A}_{1 \mathrm{~A}}{ }^{-}$. This finding is relevant to the rates of forward electron transport from $\mathrm{A}_{1 \mathrm{~A}}{ }^{-}$or $\mathrm{A}_{1 \mathrm{~B}}{ }^{-}$to the [4Fe-4S] centre $F_{X}$ and provides light on the orientation of the phylloquinone acceptors in their binding pockets in PSI. ${ }^{78}$ Furthermore, the assembly of the PsaC subunit in the PSI complex has been studied using site-specific spin labelling EPR spectroscopic techniques. ${ }^{79}$

The 3D structure of a plant PSI complex has revealed that the $\mathrm{Cu}$ atom in Pc coincides with the pseudo two-fold axis of symmetry of the electron transport path from $\mathrm{P}_{700}$ to the $\mathrm{F}_{\mathrm{X}}$ cluster. ${ }^{61}$ Electron transfer from Pc to PSI is two orders of magnitude faster in plants compared with cyanobacteria. This is probably due to more efficient Pc binding in plants, mediated by the extra 18 amino acid residues in the N-terminus of plant PsaF, which forms an amphipathic helix-loop-helix motif on the luminal side of the thylakoid membrane.

\section{Photosystem II}

Photosystem II (PSII) is responsible for the oxidation of water and reduction of plastoquinone in oxygenic photosynthesis (Fig. 1). It operates as a water:plastoquinone oxidoreductase where the transformation of light into electrochemical Gibbs energy occurs. Two types of processes take place in PSII: (i) the formation of electronically excited singlet states (excitons) by light absorption of antenna pigment-protein complexes and excitation energy transfer to the photochemically active chlorophyll pigments $\left(\mathrm{P}_{680}\right)$ in the $\mathrm{RC}$ and (ii) the electron transport from ${ }^{1} \mathrm{P}_{680}^{*}$ to an acceptor molecule thus creating a cation-anion radical pair that is stabilized by subsequent electron transport reactions. Photoexcitation of the primary electron donor $\mathrm{P}_{680}$, a chlorophyll complex located near the lumenal membrane interface, initiates the transfer of an electron to the neighboring pheophytin $a\left(\mathrm{PheO}_{\mathrm{D} 1}\right)$ to the primary plastoquinone $\left(\mathrm{Q}_{\mathrm{A}}\right)$ on the stromal side. $\mathrm{Q}_{\mathrm{A}}$ is a tightly bound species that is reduced by $\mathrm{Pheo}^{-}$forming a semiquinone $\left(\mathrm{Q}_{\mathrm{A}}{ }^{-}\right)$. Subsequently, electrons leave PSII via the secondary plastoquinone acceptor $\left(\mathrm{Q}_{\mathrm{B}}\right)$, the mobile electron acceptor of PSII. $\mathrm{Q}_{\mathrm{A}}{ }^{-}$reduces $\mathrm{Q}_{\mathrm{B}}$ first to a semiquinone $\left(\mathrm{Q}_{\mathrm{B}}{ }^{-}\right)$and then to a quinol $\left(\mathrm{Q}_{\mathrm{B}} \mathrm{H}_{2}\right)$ after a second photochemical turnover. ${ }^{15,17,19,21,22} \mathrm{Fe}$ limitation affects PSII composition and photochemical energy conversion efficiency since several cofactors are dependent on this metal, in particular, the non-heme Fe, located in the acceptor side, and the cytochrome $b_{559}$ (cyt $b_{559}$ ).

The non-heme $\mathrm{Fe}\left(\mathrm{Fe}^{2+}\right)$ is located on the stromal side of the protein close to quinones $\mathrm{Q}_{\mathrm{A}}$ and $\mathrm{Q}_{\mathrm{B}}$, within $\sim 7.5 \AA$ of either quinone (centre to centre). The $\mathrm{Fe}^{2+}$ adopts a near-octahedral ligand geometry. ${ }^{80,81}$ Four coordination sites are provided by His residues, two from D1 (His215 and His272) and two from D2 (His214 and His268). Exogenous bidentate bicarbonate fills the remaining two coordination sites. ${ }^{82}$ The available highresolution structural data of PSII derive crystals from the cyanobacteria Thermosynechococcus elongatus (pdb 1S5L, 2AXT, 3BZ1, $3 \mathrm{KZY})^{80,81,83}$ and Thermosynechococcus vulcanus (pdb 3ARC). ${ }^{84}$ Until now the experimental approach conducted in plants has not provided high resolution $3 \mathrm{D}$ structures. The X-ray $3 \mathrm{D}$ structures of PSII core complexes resolved in Thermosynechococcus elongatus proposed that either D1-Tyr246 or D2-Tyr244 provides a hydrogen bond to the oxygen of the bicarbonate ligand. The role of the non-heme Fe in PSII is not fully understood. Lightinduced Fourier transform infrared (FTIR) and EPR techniques have helped us to understand the binding site and its functional implications. The redox properties of the non-heme Fe complex are sensitive to the redox state of quinones $\mathrm{Q}_{\mathrm{A}}$ and $\mathrm{Q}_{\mathrm{B}}$. It has been suggested that it regulates the proton-coupled electron-transfer (PECT) reactions of quinone acceptors. ${ }^{85}$ This PECT transfer might be important in the photoprotective transfer of oxidative power away from $\mathrm{P}_{680}{ }^{+}$and the oxygenevolving complex (OEC) in stressed PSII centres. ${ }^{86}$ The bicarbonate ligand and Tyr residues coupled to the non-heme Fe (D1-Tyr246 or D2-Tyr244) could play a key role in the regulatory function of the Fe-bicarbonate centre. ${ }^{87,88}$

Cyt $b_{559}$ is a heme-bridged protein heterodimer composed of $\alpha$ - and $\beta$-subunits, which are encoded by the $p s b E$ and $p s b F$ genes, respectively. The $\alpha$ - and $\beta$-subunits consist of the membrane-spanning $\alpha$-helix with the amino terminal end oriented to the stroma and the carboxyl end located in the lumen of the thylakoid membrane. ${ }^{83,89,90}$ Two His residues of the $\alpha$ - and $\beta$-subunits are coordinated to the heme $\mathrm{Fe}$ as the fifth and sixth axial ligands. ${ }^{91,92}$ Polypeptide sequence analysis in various types of prokaryotic and eukaryotic organisms showed that the His position varies with the organisms. ${ }^{93}$ The heme is distanced at about $50 \AA$ from the $\mathrm{Q}_{\mathrm{A}}$ site, $25 \AA$ from the $\mathrm{Q}_{\mathrm{B}}$ site, $50 \AA$ and $25 \AA$ from pheophytins of D1 (Pheo $\left.\mathrm{D}_{\mathrm{D} 1}\right)$ and D2 $\left(\mathrm{Pheo}_{\mathrm{D} 1}\right)$ proteins, respectively (edge-to-edge distance). ${ }^{80,81,84}$ A distinct feature of cyt $b_{559}$ among heme proteins is its redox heterogeneity. The cyt $b_{559}$ has singular redox properties among $b$-type cytochromes, it exhibits several midpoint redox potential forms: a high-potential form ( $\mathrm{HP}, E_{\mathrm{m}} \approx+400 \mathrm{mV}$ ), an intermediatepotential form (IP, $E_{\mathrm{m}} \approx+200-150 \mathrm{mV}$ ), and a low-potential form $\left(\mathrm{LP}, E_{\mathrm{m}} \approx+100 \mathrm{mV}\right){ }^{94,95}$ The $\mathrm{HP}$ form is very labile as it has only been observed in intact chloroplasts and some isolated PSII preparations. The degree of the heme exposure to solvents and its environmental hydrophobicity seem to modulate the cyt $b_{559}$ redox properties. ${ }^{94-97}$ The molecular mechanisms responsible for these singular redox properties are mainly unknown, although several hypotheses have been proposed. ${ }^{96,98,99}$ Reduced cyt $b_{559}$ acts an electron donor for $\mathrm{P}_{680}{ }^{+}$when the oxygen-evolving activity is impaired. ${ }^{100-107}$ In this case the photo-oxidation of cyt $b_{559}$ is mediated by nearby molecules of chlorophyll and $\beta$-carotene. ${ }^{101,108}$ Reduction of oxidized cyt $b_{559}$ by plastoquinols proceeds biphasically comprising a fast component with a rate constant higher than $10 \mathrm{~s}^{-1}$, named phase I, followed by a slower dark reaction with a rate constant of $2.7 \mathrm{~min}^{-1}$ at $\mathrm{pH} 6.5$, named phase II. Recent investigations have revealed that these two 
components of the cyt $b_{559}$ redox reaction reflect two redox equilibria attaining in different time domains. The phase I of cyt $b_{559}$ reduction could be associated with a one-electron redox equilibrium between oxidized cyt $b_{559}$ and the photosystem II-bound plastoquinol. On the other hand, the phase II would be associated with equilibration of cyt $b_{559}$ redox forms with the quinone pool. The quinone site involved in phase I of cyt $b_{559}$ reduction is considered to be the site regulating the redox potential of cyt $b_{559}$, which could accommodate quinone, semiquinone and quinol forms. ${ }^{108}$

EPR techniques have been used to characterize this protein because the ferric state of cyt $b_{559}$ is paramagnetic. The principal values of the $g$-tensor are $g_{z z} \approx 3.05-2.9, g_{y y} \approx 2.26-2.15$ and $g_{x x} \approx 1.5-1.4$, which correspond to a low spin (LS) heme centre. ${ }^{94,109}$ Slight modifications of $g$-tensor values are observed depending on the preparation and purification of the samples. A two dimensional (2D) ESSEM HYSCORE study allowed to obtain the hyperfine and quadrupolar coupling tensors of heme and imidazole bonding nitrogen atoms in cyt $b_{559}$ from spinach. ${ }^{110}$ These studies indicated that the unpaired electron is confined in a non-bonding $\mathrm{Fe}$ orbital with a negligible nitrogen p-orbital contribution. The orientation of the two parallel imidazole rings of the axial His ligands with respect to heme was also calculated.

Despite that cyt $b_{559}$ is strictly required for proper function of PSII, it is not involved in the linear electron transport chain from water to plastoquinone. Instead of that the participation of cyt $b_{559}$ in the cyclic electron transport around PSII has been proposed mainly based on the ability of the heme Fe to accept and donate an electron from the electron acceptor and to the electron donor side of PSII, respectively. Additionally, the possible oxidase and reductase enzymatic activity of cyt $b_{559}$ in protection from photoinhibition has been proposed. ${ }^{111}$

\section{Cytochrome $b_{6} f$ complex}

The cytochrome $b_{6} f$ (cyt $b_{6} f$ ) complex provides the electronic connection between the PSI and PSII reaction centres in oxygenic photosynthesis and generates a transmembrane electrochemical proton gradient for adenosine triphosphate synthesis (Fig. 1). ${ }^{112}$ Within the cyt $b_{6} f$ complex, one electron is transferred from doubly reduced dihydro-plastoquinone $(\mathrm{PQH} 2)$ to a high-potential electron transfer chain, consisting of the Rieske [2Fe-2S] protein and cytochrome $f$ on the electropositive side of the membrane. Besides the cyt $b_{6} f$ complex seems to be involved in redox signaling and state transition. ${ }^{82}$ The core of the cyt $b_{6} f$ complex is similar to the analogous respiratory cytochrome $b c_{1}$ complex, but the domain arrangement outside the core and the complement of prosthetic groups are strikingly different. The cyt $b_{6} f$ complex from plants contains five Fe redox cofactors: (i) the two $b$ hemes $\left(b_{\mathrm{n}}\right.$ and $\left.b_{\mathrm{p}}\right)$, components of cyt $b_{6}$ and bound noncovalently to the protein; (ii) the heme of cyt $f$; (iii) the high redox potential [2Fe-2S] cluster of the Rieske protein (about $E_{\mathrm{m}} \approx+300 \mathrm{mV}$ ); (iv) the FAD moiety of the ferredoxin:NADP+ reductase found in the cyt $b_{6} f$ complex from spinach ${ }^{113}$ and presumably present in other plant species. The Fe cofactors of hemes $b_{\mathrm{n}}$ and $b_{\mathrm{p}}$ and cyt $f$, and that of the Rieske protein are common to bacteria but the latter has no analogue in the cytochrome $b c_{1}$ complex. This fact could indicate that plant cyt $b_{6} f$ complex has a different function, probably as a protein kinase regulator.

In plants, the cyt $b_{6} f$ complex is composed of at least nine protein subunits of dual genetic origin. Two subunits, PetC (Rieske [2Fe-2S] subunit) and PetM, are encoded by nuclear genes. The other subunits are encoded in plastid chromosomes. Among these, three genes encode large (16-31 kDa) subunits PetA, PetB, and PetD, that contain the redox cofactor groups of cyt $f$, cyt $b_{6}$, and subunit IV, respectively. The remaining low-molecular-weight (3.3-4.1 kDa) subunits, PetG, PetL, and PetN, are hydrophobic and span the membrane once. ${ }^{114,115}$ Lack of the Rieske protein affects the stability of cyt $b_{6} f$ complex and influences the level of other thylakoid proteins, particularly those of PSII. ${ }^{116}$ It has been observed that in the knock-out allele petc-2 mutant, linear electron flow is blocked, leading to an altered redox state of both the primary quinone acceptor $\mathrm{Q}_{\mathrm{A}}$ of PSII and the reaction centre chlorophyll $\mathrm{P}_{700}$ of PSI.

Three-dimensional structures of cyt $b_{6} f$ complexes from Chlamydomonas reinhardtii (pdb 1Q90), Mastigocladus laminosus (pdb 1VF5), and Nostoc sp. PCC 7120 (pdb 4H44) have been determined by X-ray crystallography. ${ }^{115,117,118}$ The cyt $b_{6} f$ complex isolated from spinach thylakoid membranes contains one additional subunit, FNR, that is bound more weakly to the complex, and is not present in the cyanobacterial $b_{6} f$ complex. ${ }^{113}$ Reconstitution experiments in vitro have shown that the Rieske [2Fe-2S] protein of cyt $b_{6} f$ from spinach must be in a partially folded conformation to incorporate an appropriate $[2 \mathrm{Fe}-2 \mathrm{~S}]$ cluster. Upon cluster integration, further folding occurs, allowing the Rieske protein to attain a final native structure. $^{119}$

EPR techniques have helped to characterize the geometry and environment of Fe-S clusters within cyt $b_{6} f$ complex as well as its redox reactions. ${ }^{120-125}$ Most of these studies were developed in cyanobacterial systems but data from spinach cyt $b_{6} f$ were also reported. The values of the $g$-tensors calculated are $g_{z z}=3.60, g_{y y}=1.35$ and $g_{x x}=1.1$, and $g_{z z}=3.51, g_{y y}=1.69$ and $g_{x x}=0.9$ for cyt $b$ and cyt $f$, respectively.

\section{Ferredoxin}

Ferredoxin (Fd) is a small [2Fe-2S] cluster-containing protein with low midpoint redox potential $\left(E_{\mathrm{m}} \approx-423-(-) 345 \mathrm{mV}\right)$ found in all oxygenic photosynthetic organisms. Formation of holoferredoxin occurs in the chloroplast stroma after import and processing of the preprotein..$^{126-128} \mathrm{Fd}$ is the first soluble acceptor of electrons on the stromal side of the chloroplast electron transport chain. It transfers electrons from PSI to $\mathrm{NADP}^{+}$via the Fd:NADP $(\mathrm{H})$ reductase (FNR) for the photoreduction of $\mathrm{NADP}^{+}$to NADPH (Fig. 1). The plastidic FNR is a flavin adenine dinucleotide (FAD) containing flavoenzyme, which efficiently catalyzes the electron transfer from $\mathrm{Fd}$ to $\mathrm{NADP}^{+}$ via its flavin cofactor. Thus, Fd determines the distribution of these electrons to different metabolic reactions. This makes Fd a crucial determinant of the electron transfer between the 
thylakoid membrane and a variety of soluble enzymes dependent on these electrons. ${ }^{129}$ The plant-type [2Fe-2S] Fd functions not only in photosynthesis but also in the assimilation of nitrogen and sulphur and in the regulation of carbon assimilation. ${ }^{130}$ Therefore, the Fd family is composed of several isoforms that share high sequence homology but differ in functional characteristics. In leaves, at least two isoforms conduct linear and cyclic photosynthetic electron transport around PSI. Recently, a novel Fd protein (FdC1) localized in chloroplasts from higher plants has been found, which is capable of alternative electron partitioning under conditions of PSI acceptor limitation. ${ }^{131}$ FdC1 is capable of accepting electrons from PSI, but cannot support photoreduction of NADP ${ }^{+}$. Redox potentiometry showed that it had a more positive redox potential than photosynthetic Fds by around $E_{\mathrm{m}} \approx+220 \mathrm{mV}$. These results indicate that FdC1 electron donation to FNR is prevented because it is thermodynamically unfavorable.

The X-ray 3D structure of plant-type Fd has been resolved from Spirulina platensis (pdb 4FXC), Spinacia oleracea, spinach, (pdb 1FNB, 1FNC, 1FND), Pisum sativum, pea, (pdb 2XNC, 4AF7), Capsicum, paprika, (pdb 1SM4) and Aphanothece sacrum (pdb 3AV8). ${ }^{132-137}$ These 3D structures reveal a fold consisting of a four-stranded $\beta$-sheet with an $\alpha$-helix packed across its face, in which the $[2 \mathrm{Fe}-2 \mathrm{~S}]$ cluster is located close to the molecular surface in the loop between the $\alpha$-helix and the third $\beta$-strand. All of them have a common main-chain structure but certain differences are observed in the case of Aphanothece sacrum. In this case the short second $\alpha$-helix in the vicinity of the active centre is missing.

Many aspects of the Fd-FNR complex catalytic mechanism have been extensively characterized in recent years using a combination of site-directed mutagenesis, steady-state spectroscopy, transient kinetic experiments, and X-ray crystallography. ${ }^{138-140}$ These studies have demonstrated that the plant-type Fd and FNR enzyme form a weak complex and the efficient electron transfer is achieved by the specific interactions between the two proteins. The 3D structure of the Fd-FNR complex has been also determined from Zea mays, maize (pdb 1GAQ). ${ }^{141}$ The plant-type Fd and FNR enzyme form a weak complex being the intermolecular interactions mainly electrostatic through salt bridges, and the interface near the prosthetic groups hydrophobic. Many charged residues contribute to the complex formation, including Asp26, Glu29, Glu30, Asp34, Asp65 and Asp66 in spinach leaf Fd. The interactions between both proteins modulate the efficiency of electron transport. The Fd recognition site is localized in a concave region of the FAD binding domain of FNR. The redox centres in the complex, the [2Fe-2S] cluster of $\mathrm{Fd}$ and FAD of FNR, are in close proximity (ca. $6.0 \AA$ ).

Furthermore, crystals containing PSI and Fd have been obtained from cyanobacteria, ${ }^{76}$ which indicate a binding site of Fd located close to the terminal [4Fe-4S] cluster of PSI. Fd associates reversibly to the reaction centre of PSI and within the complex, Fd is photoreduced in the submicrosecond-microsecond time range before it dissociates for later interaction with other soluble electron acceptor proteins. EPR techniques were used to characterize the reduced $[2 \mathrm{Fe}-2 \mathrm{~S}]$ cluster of $\mathrm{Fd}$ in the crystals, which exhibits $g$-values of $g_{x x}=1.885, g_{y y}=1.955$, and $g_{z z}=2.05$.

\section{Fe transport pathways in chloroplast}

The biochemistry of Fe mobilization in the chloroplasts is still unknown, although in the last few years several components of Fe mobilization pathways in this organelle have been identified (see Fig. 1 and Table 1). For instance, (i) FRO7 (ferric-chelate reductase oxidase 7) localized in envelope membranes; ${ }^{142}$ (ii) MAR1/IREG3 (multiple antibiotic resistance1/iron-regulated protein3), a plastid member of the ferroportin/IREG transporter family; $^{143}$ (iii) the membrane-spanning protein PIC1 (for permease in chloroplasts 1) that mediates Fe transport across the inner envelope membrane of chloroplasts and is crucial for balancing plant Fe metabolism; ${ }^{144}$ (iv) the non-intrinsic ABC protein (NAP)_14, NAP14, the closest homolog of the Fut system in cyanobacteria, which could either be part of an Fe transporter complex or be a plastid regulator of Fe homeostasis. ${ }^{145}$ The Fe-S clusters are assembled in chloroplasts; this process is complex and requires the mobilization of both Fe and sulphur, and its insertion into apo-proteins. The NAP14 protein has been suggested to be involved in [Fe-S] cluster biogenesis. ${ }^{14}$ In addition to membrane transporters, soluble metallochaperones also participate in the intracellular trafficking of metal ions and provide $\mathrm{Fe}$ to the active sites. A few chaperones involved in the transfer of heme or [Fe-S] cluster to apo-proteins have been characterized. ${ }^{7}$

\section{Proteins involved in Fe metalloprotein assembly}

The heme group is synthesised from protoporphyrinogen IX in chloroplasts and then incorporated into cytochrome apoproteins. The formation of intracellular [Fe-S] clusters also takes place in chloroplasts. These processes require complex biosynthetic machinery. Three different types of Fe-S cluster biosynthetic systems have been discovered, and all of them require a cysteine desulfurase and the participation of an $\mathrm{Fe}-\mathrm{S}$ cluster scaffolding protein. Then the assembled Fe-S cluster is transferred from scaffolds to target apo-proteins with free Cys residues to receive the cluster. ${ }^{146}$ This transfer mechanism could need chaperones or a carrier protein. Despite the importance of Fe-S proteins in higher plant plastids, little is known regarding plastidic Fe-S cluster assembly. For instance, the source of sulphur is cysteine but that of $\mathrm{Fe}$ is not known, although we could speculate that ferritin could be the source of Fe.

In chloroplasts, the first component of the assembly machinery of Fe-S clusters identified was the cysteine desulfurase NFS2/CpNifs, ${ }^{7,147,148}$ homologous to the bacterial cysteine desulfurase SufS, a component of the SUF system for sulphur mobilization (Fig. 1). In bacteria, the SUF system consists of six proteins encoded by the sufoperon (sufABCDSE). In Arabidopsis, three proteins homologous to bacterial Suf proteins, AtNAP1, AtNAP6, AtNAP7, have been identified and all of them are targeted to chloroplasts. ${ }^{149}$ This finding indicates the remarkable evolutionary conservation of the SUF system. 
Table 1 Metalloproteins in plant photosynthesis and proteins involved in their assembly and metal homeostasis in chloroplasts

\begin{tabular}{|c|c|c|c|c|c|c|}
\hline $\begin{array}{l}\text { Metal } \\
\text { cofactor }\end{array}$ & Protein name & Location & Function & UniProt code & Structure PDB & Ref. \\
\hline \multirow[t]{3}{*}{$\mathrm{Cu}$} & Plastocyanin & Lumen & Electron transport & & 1YLB, 1AG6, 1BYO, 4DP0 & $\begin{array}{l}9,12-14 \\
15-30\end{array}$ \\
\hline & AtPETE1 & & & P11490 & & 10,11 \\
\hline & AtPETE2 & & & P42699 & & \\
\hline \multirow[t]{4}{*}{ Transport } & PAA1/AtHMA6 & $\begin{array}{l}\text { Envelope } \\
\text { membrane }\end{array}$ & $\mathrm{Cu}^{+} \mathrm{P}_{1 \mathrm{~B}}-\mathrm{ATPase}$ & Q9SZC9 & & $7,34-36$ \\
\hline & PAA2/AtHMA8 & $\begin{array}{l}\text { Thylakoid } \\
\text { membrane }\end{array}$ & $\mathrm{Cu}^{+} \mathrm{P}_{1 \mathrm{~B}}-\mathrm{ATPase}$ & B9DFX7 & & $7,34-36$ \\
\hline & AtHMA1, HvHMA1 & $\begin{array}{l}\text { Envelope } \\
\text { membrane }\end{array}$ & $\mathrm{Cu}^{++} / \mathrm{Zn}^{++} \mathrm{P}_{1 \mathrm{~B}}-$ ATPase & Q9M3H5 & & $7,37-39$ \\
\hline & CCS & Cytosol & $\mathrm{Cu}^{+}$-chaperone & Q9LD47 & & 7,40 \\
\hline \multirow[t]{11}{*}{$\mathrm{Fe}$} & Photosystem I & & & & & \\
\hline & $\begin{array}{l}{[4 \mathrm{Fe}-4 \mathrm{~S}], \mathrm{F}_{\mathrm{X}}, \mathrm{F}_{\mathrm{A}}, \mathrm{F}_{\mathrm{B}} \text { (PsbA, }} \\
\text { PsbB, PsbC) }\end{array}$ & $\begin{array}{l}\text { Thylakoid } \\
\text { membrane }\end{array}$ & Electron transport & $\begin{array}{l}\text { P56766, P56767, } \\
\text { P62090 }\end{array}$ & 1QZV, 2O01, 2WSC, 3LW5 & $43-56$ \\
\hline & Photosystem II & & & & & \\
\hline & Non-heme Fe (PsbA, PsbD) & $\begin{array}{l}\text { Thylakoid } \\
\text { membrane }\end{array}$ & Electron transport & P83755, P56761 & 1S5L, 2AXT, 4IL6 & $60-64$ \\
\hline & Cyt $b_{559}(\mathrm{PsbE}, \mathrm{PsbF})$ & $\begin{array}{l}\text { Thylakoid } \\
\text { membrane }\end{array}$ & Electron transport & P56779, P62095 & & \\
\hline & Cyt $b_{6} f$ complex & & & & & $65-70,72-80$ \\
\hline & Rieske $[2 \mathrm{Fe}-2 \mathrm{~S}]$ protein (PetC) & $\begin{array}{l}\text { Thylakoid } \\
\text { membrane }\end{array}$ & Electron transport & Q9ZR03 & 1Q90, 1VF5, 4H44 & $81-94$ \\
\hline & Cyt $f$ (PetA) & $\begin{array}{l}\text { Thylakoid } \\
\text { membrane }\end{array}$ & Electron transport & A4QJZ7 & & \\
\hline & Cyt $b_{6}$, hemes $b_{\mathrm{n}}$ and $b_{\mathrm{p}}$ (PetB) & $\begin{array}{l}\text { Thylakoid } \\
\text { membrane }\end{array}$ & Electron transport & P56773 & & \\
\hline & Ferredoxin & & & & & \\
\hline & $\begin{array}{l}\text { Rieske }[2 \mathrm{Fe}-2 \mathrm{~S}] \text { protein (FD1, } \\
\text { FD2, FD3) }\end{array}$ & Stroma & Electron transport & $\begin{array}{l}\text { O04090, P16972, } \\
\text { Q9ZQG8 }\end{array}$ & $\begin{array}{l}\text { 4FXC, 1FNB, 1FNC, 1FND, } \\
2 \mathrm{XNC}, 4 \mathrm{AF} 7,1 \mathrm{SM} 4,3 \mathrm{AV} 8, \\
1 \mathrm{GAQ}\end{array}$ & $52,95-110$ \\
\hline \multirow[t]{4}{*}{ Transport } & FRO7 & $\begin{array}{l}\text { Envelope } \\
\text { membrane }\end{array}$ & $\begin{array}{l}\mathrm{Fe}^{+++} \text {chelate } \\
\text { reductase }\end{array}$ & Q3KTM0 & & 111 \\
\hline & MAR1/IREG3 & $\begin{array}{l}\text { Envelope } \\
\text { membrane }\end{array}$ & $\begin{array}{l}\text { Fe chelate } \\
\text { transporter }\end{array}$ & Q8W4E7 & & 112 \\
\hline & PIC1 (TIC21) & $\begin{array}{l}\text { Inner envelope } \\
\text { membrane }\end{array}$ & $\begin{array}{l}\text { Permease membrane } \\
\text { transporter }\end{array}$ & Q9SHU7 & & 113 \\
\hline & NAP14 (ABCI11) & Stroma & ABC-ATPase & Q8LEF6 & & 8,114 \\
\hline \multirow[t]{9}{*}{ Assembly } & NFS2/CpNifs & Stroma & Cysteine desulfurase & Q93WX6 & & $4,116,117$ \\
\hline & AtNAP1, AtNAP6, AtNAP7 & Stroma & ABC-ATPase & Q5S2C4 & & 118 \\
\hline & $\begin{array}{l}\text { AtCnfU-IVa, AtCnfU-IVb, } \\
\text { AtCnfU-V (NifU3, NifU1, NifU2) }\end{array}$ & Stroma & $\begin{array}{l}\text { Scaffold for } \mathrm{Fe} / \mathrm{S} \\
\text { cluster }\end{array}$ & $\begin{array}{l}\text { B9DGD5, } \\
\text { Q93W77, Q3W20 }\end{array}$ & $2 Z 51$ & 119,120 \\
\hline & HCF101 & Stroma & $\begin{array}{l}\text { Scaffold for }[4 \mathrm{Fe}-4 \mathrm{~S}] \\
\text { cluster }\end{array}$ & Q6STH5 & & $48,121-123$ \\
\hline & HCF164 & $\begin{array}{l}\text { Thylakoid } \\
\text { lumen }\end{array}$ & $\begin{array}{l}\text { Thiol-disulfide } \\
\text { oxidoreductase }\end{array}$ & $\mathrm{O} 23166$ & & 126,127 \\
\hline & PPD1 & $\begin{array}{l}\text { Thylakoid } \\
\text { lumen }\end{array}$ & $\begin{array}{l}\text { PsbA and PsbB } \\
\text { insertion }\end{array}$ & P61843 & & 125 \\
\hline & Ycf3, Ycf4 & $\begin{array}{l}\text { Thylakoid } \\
\text { membrane }\end{array}$ & {$[4 \mathrm{Fe}-4 \mathrm{~S}]$ insertion } & E5KCJ8 & & 125 \\
\hline & Y3IP1 & $\begin{array}{l}\text { Thylakoid } \\
\text { membrane }\end{array}$ & {$[2 \mathrm{Fe}-2 \mathrm{~S}]$ insertion } & Q9LSE4 & & 125 \\
\hline & System IV/CCB1, CCB2, CCB4 & Chloroplast & Scaffold for cyt $b_{6}$ & Q9FJ81, Q6NQK9 & & $128-130$ \\
\hline \multirow[t]{2}{*}{ Mn } & Photosystem II & Thylakoid & Water-splitting & P83755, P56761 & 1S5L, 2AXT, 4IL6 & $58,59,71$ \\
\hline & $\mathrm{Mn}_{4} \mathrm{CaO}_{5}$-cluster (PsbA, PsbD) & membrane & & & & $131-140$ \\
\hline \multirow[t]{3}{*}{ Assembly } & Psb27 & $\begin{array}{l}\text { Thylakoid } \\
\text { lumen }\end{array}$ & Scaffold for PSII & Q9LR64 & & 141,142 \\
\hline & PsbP & $\begin{array}{l}\text { Thylakoid } \\
\text { lumen }\end{array}$ & $\begin{array}{l}\mathrm{Ca}^{2++} \text { and } \mathrm{Cl}^{-} \text {bind- } \\
\text { ing in PSII }\end{array}$ & Q42029 & & 143,144 \\
\hline & PsbQ & $\begin{array}{l}\text { Thylakoid } \\
\text { lumen }\end{array}$ & $\begin{array}{l}\mathrm{Ca}^{2++} \text { and } \mathrm{Cl}^{-} \text {bind- } \\
\text { ing in PSII }\end{array}$ & Q9XI73 & & 143,144 \\
\hline Transport & MntABC & $?$ & $\begin{array}{l}\text { Permease } \mathrm{ABC} \\
\text { transporter }\end{array}$ & & & 36,147 \\
\hline \multirow[t]{2}{*}{$\mathrm{Zn}$} & $\beta$-Carbonic anhydrase & Stroma & Hydration of $\mathrm{CO}_{2}$ & P17067 & $1 \mathrm{EKJ}$ & 148,149 \\
\hline & Zn-finger protein (LQY1) & $\begin{array}{l}\text { Thylakoid } \\
\text { membrane }\end{array}$ & disulfide-isomerase & Q8GSJ6 & & 150,151 \\
\hline Transport & AtHMA1, HvHMA1 & $\begin{array}{l}\text { Envelope } \\
\text { membrane }\end{array}$ & $\mathrm{Cu}^{++} / \mathrm{Zn}^{++} \mathrm{P}_{1 \mathrm{~B}}-\mathrm{ATPase}$ & Q9M3H5 & & $7,37-39$ \\
\hline
\end{tabular}


Additionally, other chloroplast-localized proteins have been identified that bind and transfer Fe-S clusters in Arabidopsis, such as AtCnfU-V, AtCnfU-IVa, AtCnfU-IVb, homologues to cyanobacterial CnfU and HCF101. These findings demonstrate that plant Fe-S cluster biogenesis occurs in plastids.

CnfU was the first Fe-S cluster biosynthetic scaffold whose ability to transfer its bound cluster to an apo-substrate was demonstrated in vitro. ${ }^{150}$ It is required for biogenesis of $\mathrm{Fd}$ and PSI in chloroplasts. The X-ray 3D structure at $1.35 \AA$ resolution of the metal-free dimer of AtCnfU-V (pdb 2Z51) revealed that $\mathrm{N}$-terminal domains of the two monomers are linked together through two intermolecular disulfide bonds between the CXXC motifs. At the dimer interface, a total of four Cys sulphur atoms provide a Fe-S cluster assembly site surrounded by uncharged but hydrophilic structurally mobile segments. The C-terminal domain of one monomer interacts with the N-terminal domain of the opposing monomer and thereby stabilizes dimer formation. Additionally, Fe K-edge X-ray absorption spectroscopic analysis with the holo-AtCnfU-V dimer in solution suggested the presence of a typical [2Fe-2S]-type cluster coordinated by four thiolate ligands. ${ }^{151}$

Proteins involved in cofactor biogenesis and cofactor attachment to PSI have been reviewed. ${ }^{67}$ The High Chlorophyll Fluorescence 101 (HCF101) is involved in the assembly of [4Fe-4S] cluster containing complexes in Arabidopsis thaliana by transiently binding $[4 \mathrm{Fe}-4 \mathrm{~S}]$ clusters. It functions as a scaffold for $[4 \mathrm{Fe}-4 \mathrm{~S}]$ cluster insertion. ${ }^{152-154}$ It has been reported that HCF101 would be involved in metal co-factor maturation and/or stability of $[4 \mathrm{Fe}-4 \mathrm{~S}]$-containing complexes but it is not required for assembly and/or stability of plastidic [2Fe-2S] clusters since hcf101 mutant Arabidopsis plants accumulate normal levels of the $[2 \mathrm{Fe}-2 \mathrm{~S}]$ cluster-containing proteins such as Fd and Rieske (PetC). Although a set of PSI assembly factors has been identified the mechanism for PSI assembly is still not well understood compared with the detailed knowledge of the biogenesis of PSII. ${ }^{155}$

PPD1 (PsbP-domain protein_1) is a nuclear-encoded thylakoid lumenal protein associated with PSI but is not an integral subunit of PSI. It interacts directly and specifically with some lumenal loops of PsaB and PsaA and assists the proper folding and integration of PsaA and PsaB into the thylakoid membrane. ${ }^{156}$ Among chaperones that function as a scaffold for the assembly of the PSI complex, Hypothetical Chloroplast Reading Frame Number3 (Ycf3) and Ycf4, encoded by chloroplast genes, have been demonstrated to play an important role in the assembly of the PSI complex in the alga Chlamydomonas reinhardtii. The Ycf3-Interacting Protein1 (Y3IP1), a nucleusencoded thylakoid protein, cooperates with Ycf3 in the assembly of the stable PSI complex in higher plants.

Several proteins have been reported to be involved in the cyt $b_{6} f$ complex such as the HCF164, a membrane-anchored thioredoxin-like protein, and the system IV or CCB proteins. The HCF164 protein receives reducing equivalents from stromal m-type thioredoxin across the thylakoid membrane and mediates reduction of target proteins in the thylakoid lumen. The cyt $f$ and Rieske [Fe-S] proteins, components of the cyt $b_{6} f$ complex, were identified as potential target proteins of HCF164. ${ }^{157}$ In Arabidopsis, the hcf164 mutant was found to be impaired in the stable assembly of the cyt $b_{6} f$ complex within thylakoid membranes. ${ }^{158}$

In Chlamydomonas, the heme biogenesis pathway requires the system IV or CCB (cofactor assembly, complex C $\left(b_{6} f\right)$, subunit B (PetB)) for heme covalent binding onto cyt $b_{6}$. Four nuclear CCB loci that control heme $c_{\mathrm{i}}$ maturation were identified. ${ }^{159-161}$ In Arabidopsis ccb1, ccb2, and ccb4 mutants show a phenotype characterized by a deficiency in the accumulation of the subunits of the cyt $b_{6} f$ complex and lack covalent heme binding to cyt $b_{6}$. This demonstrates the role in the heme $c_{\mathrm{i}}$ binding of CCB1, CCB2 and CCB4. The binding is via a single thioether bond and, thus, the covalent heme is regarded as $c$-type. This system is found in all organisms with oxygenic photosynthesis.

In metalloproteins driving redox reactions constituent subunits of the complexes are also required for optimized conformation and active binding site stabilization. In the cyt $b_{6} f$ complex, assembly studies revealed that PetL, protein located at the periphery of the complex opposite the dimerization axis, is primarily required for proper conformation of the Rieske [2Fe-2S] protein, leading to stability and formation of dimeric cyt $b_{6} f$ complexes. ${ }^{154}$ This positioning does not support the idea that the protein is directly involved in the dimerization process. Yet, it is likely that lack of PetL destabilizes the attachment of the Rieske [2Fe-2S] protein, either via conformational changes or its association with the cyt $b_{6} f$ complex leading to destabilization of the dimer.

\section{Manganese}

Manganese ( $\mathrm{Mn}$ ) is a $3 \mathrm{~d}^{5}$ element and a redox-active transition metal that exist in several oxidized states, $\mathrm{Mn}^{2+}, \mathrm{Mn}^{3+}, \mathrm{Mn}^{4+}$, $\mathrm{Mn}^{6+}, \mathrm{Mn}^{7+}$, which is required for plant growth. Its deficiency is often confused with Fe deficiency. In plant photosynthesis, Mn is mainly required to form the Mn-cluster in PSII, located in the donor side region (Fig. 1). This cluster catalyses the wateroxidation process within the OEC complex. It is known for some time that there are at least five intermediate states leading to the formation of dioxygen, known as $\mathrm{S}_{i}$-states. The sequential advancement from $S_{0}$ to $S_{4}$ is driven by each photochemical turnover of the PSII reaction centre as depicted in the $\mathrm{S}_{i}$-state cycle. The progression through the S-states to $\mathrm{S}_{4}$ results in the storing of four oxidising equivalents, which are reduced in the final step $\left(S_{4}\right.$ to $\left.S_{0}\right)$ by four electrons derived from two substrate water molecules with the concomitant formation of dioxygen. The atomic and electronic structure of the Mn-cluster in each $\mathrm{S}_{i}$ state has been extensively studied. The X-ray 3D structure of PSII at $3.5 \AA$ (pdb 1S5L) from Thermosynechococcus elongatus determined by Ferreira et al. ${ }^{80}$ suggested that the Mn-cluster contains three $\mathrm{Mn}$ ions and a $\mathrm{Ca}^{2+}$ ion forming a cubane-like structure $\left(\mathrm{Mn}_{3} \mathrm{CaO}_{4}\right)$ and a fourth $\mathrm{Mn}$ ion is linked to the cubane by mono- $\mu$-oxo bridges via one of the oxo groups of the cubane and is adjacent to the $\mathrm{Ca}^{2+}$. More recently, the 3D structure of PSII at $1.9 \AA$ resolution (pdb 3ARC) from 
Thermosynechococcus vulcanus ${ }^{84}$ has shown that five oxygen atoms served as $\mu$-oxo bridges linking the five metal atoms, and four water molecules are bound to the $\mathrm{Mn}_{4} \mathrm{CaO}_{5}$ cluster. Some of these water molecules may serve as substrates for dioxygen formation. The bond lengths between the oxygens and the $\mathrm{Ca}$ in the cubane are generally in the range of 2.4-2.5 $\mathrm{\AA}$, and those between the oxygen and $\mathrm{Mn}$ are in the range of 1.8-2.1 $\mathrm{A}$. However, the bond length between one of the oxygens at the corner of the cubane (O5) and the $\mathrm{Ca}$ is $2.7 \AA$, and those between $\mathrm{O} 5$ and the $\mathrm{Mn}$ are in the range of 2.4-2.6 $\AA$. These differences in bond lengths suggest that the $\mathrm{Mn}_{3} \mathrm{CaO}_{4}$ cubane structure is not an ideal symmetric one. Until now no 3D structures of PSII and Mn-cluster from plants have been resolved. It is worth noting that the PSII complex from cyanobacteria has distinct features compared to those of plants. In particular the presence of cytochrome $c 550$, which with other extrinsic proteins stabilizes the oxygen-evolving complex and protects the $\mathrm{Mn}_{4} \mathrm{CaO}_{5}$ cluster. ${ }^{84}$ An electron transport between cyt $c 550$ and the nearest Mn-cluster has been proposed.

Surrounding the $\mathrm{Mn}_{4} \mathrm{CaO}_{5}$-cluster are positioned a number of amino acid residues that either provide ligands to the metal ions or act to facilitate hydrogen bonding networks. The ligation pattern and the geometric positions of the metal atoms may have important consequences for the mechanisms of water splitting, in the deprotonation of the substrate water molecules, and $\mathrm{O}-\mathrm{O}$ bond formation. All of the amino-acid residues coordinated to the $\mathrm{Mn}_{4} \mathrm{CaO}_{5}$ cluster have been identified. ${ }^{84}$ Most of the distances of the ligands to $\mathrm{Mn}$ are in the range of 2.0-2.3 A. These residues, together with the oxo bridges and waters, give rise to a saturating ligand environment for the $\mathrm{Mn}_{4} \mathrm{CaO}_{5}$ cluster (each of the Mn has six ligands whereas the $\mathrm{Ca}$ has seven ligands).

In the last few years, the combination of structural data from X-ray crystallography, EXAFS, EPR techniques, the use of isotopic labelling, synthetic chemistry and computational analysis have provided chemical models for the water splitting reaction and the formation of dioxygen. ${ }^{162-171}$ Two water molecules are proposed to coordinate the outer $\mathrm{Mn}$ of the $\mathrm{Mn}_{4} \mathrm{CaO}_{5}$ cluster in the $\mathrm{S}_{2}$ state. It has been established that protonation states of water ligands and oxo bridges are intimately involved in tuning the electronic structures and oxidation potentials of the OEC in PSII. Although protons are practically invisible in protein crystallography, their effects on the electronic structure and magnetic properties of metal active sites have been probed using EPR techniques. Furthermore, in order to elucidate the possible location of water molecules crystal structure of $\mathrm{Sr}^{2+}$-substituted PSII from Thermosynechococcus vulcanus (pdb 4IL6) ${ }^{172}$ has been analyzed. The results suggest a weak binding and rather mobile nature of the water molecule (W3), which in turn implies the possible involvement of this water molecule as a substrate in the $\mathrm{O}-\mathrm{O}$ bond formation.

Despite these advances, a realistic mechanism for the photosynthetic water splitting reaction is still unresolved due to the heterogeneity of this system and the serious experimental difficulties found. Recently, it has been pointed out that the available experimental structures are a mixture of states containing highly reduced forms, with the largest contribution (almost 60\%) from the $\mathrm{S}_{3}$-state, $\mathrm{Mn}$ (II,II,III,III). ${ }^{169}$

\section{Proteins assisting Mn-cluster assembly}

The biogenesis and oxygen-evolving activity of PSII is dependent on a number of accessory proteins not found in the crystallized dimeric complex. These include Psb27, a small lipoprotein attached to the lumenal side of PSII, which has been assigned a role in regulating the assembly of the $\mathrm{Mn}_{4} \mathrm{CaO}_{5}$ cluster catalysing water oxidation. ${ }^{173}$ The X-ray 3D structure of the soluble domain of Psb27 from Thermosynechococcus elongatus to a resolution of $1.6 \AA$ (pdb 2Y6X) revealed potential binding sites for Psb27. ${ }^{174}$ However, the Psb27-binding site in PSII from higher plants is currently unknown.

The extrinsic PsbP and PsbQ protein subunits of PSII regulate the binding properties of the essential cofactors $\mathrm{Ca}^{2+}$ and $\mathrm{Cl}^{-}$at the donor side of PSII and stabilizes the $\mathrm{Mn}_{4} \mathrm{CaO}_{5}$ cluster, but the binding site and topology in PSII have yet to be clarified. ${ }^{175,176}$ PsbP induces conformational changes around the catalytic $\mathrm{Mn}_{4} \mathrm{CaO}_{5}$ cluster required for $\mathrm{Ca}^{2+}$ and $\mathrm{Cl}^{-}$retention, and the N-terminal region of PsbP is essential for this reaction. In PsbP, the residues His144 and Asp165, which are suggested to be located at the metal binding site, have a crucial role in the functional interaction between PsbP and PSII. Moreover, cross-linking experiments showed that the His144Ala mutation affects the direct interaction between PsbP and the Cyt $b_{559} \propto$ subunit of PSII (the PsbE protein). In the PsbP structure, His144 and Asp165 form a salt bridge. PsbQ stabilizes PsbP binding contributing to the maintenance of the catalytic $\mathrm{Mn}_{4} \mathrm{CaO}_{5}$ cluster function, in plant PSII.

\section{Mn transport pathways in chloroplast}

At the cellular level, $\mathrm{Mn}^{2+}$ accumulates predominantly in the vacuole and to some extent in chloroplasts, and can be associated with the cell wall fraction. ${ }^{177}$ In Arabidopsis AtNRAMP3 and AtNRAMP4 transporters, which remobilize vacuolar Mn in adult leaves, are required for functional PSII. ${ }^{178}$ Under $\mathrm{Mn}$ deficiency, nramp3nramp4 double mutant plants contain less functional PSII than the wild type. The AtNRAMP3 and AtNRAMP4 transporters export Mn through the vacuole prior to the import into chloroplasts of mesophyll cells. In cyanobacteria, the Mn high-affinity MntABC transport system is induced under Mn deficiency. ${ }^{54,179}$ The inactivation of this transport system results in a loss of PSII activity. However, homologues of the MntABC transporter were not found in chloroplasts. To date no plant membrane transporter has been found to import Mn within the chloroplast.

\section{Zinc}

Zinc $(\mathrm{Zn})$ is a $3 \mathrm{~d}^{10}$ element and the second most abundant transition metal in living organisms after Fe. It is redox-stable under physiological conditions as a result of a complete d-shell of electrons. In plant photosynthesis, $\mathrm{Zn}$ is involved in the catalytic function of the chloroplastic $\beta$-carbonic anhydrase $(\beta-\mathrm{CA})$ enzyme, a Zn-containing metalloenzyme that catalyzes 
the rapid inter-conversion of $\mathrm{CO}_{2}$ and $\mathrm{H}_{2} \mathrm{O}$ into $\mathrm{HCO}_{3}{ }^{-}$ions. ${ }^{180}$ Additionally, Zn-finger proteins that can regulate transcription through site-specific interactions play a role in photosynthesis (Fig. 1).

\section{Carbonic anhydrase}

This ancient enzyme is found in three distinct isoforms (called $\alpha-, \beta$ - and $\gamma$-CA). The plant CA belongs to the $\beta$-type. The primary role of this enzyme is to minimize resistance to the diffusion of $\mathrm{CO}_{2}$ from the stomatal air spaces, where $\mathrm{CO}_{2}$ is initially absorbed, to the chloroplast stroma where carbon is fixed by the enzyme RuBisCO. In $\mathrm{C}_{4}$ plants the protein is expressed predominantly in the cytoplasm of mesophyll cells, where by converting $\mathrm{CO}_{2}$ to $\mathrm{HCO}_{3}{ }^{-}$it provides a substrate for phosphoenolpyruvate carboxylase and is thus an integral component of the $\mathrm{CO}_{2}$ concentrating mechanism. In the more common $\mathrm{C}_{3}$ plants, $\beta$-CA is a major component of leaf protein $(0.5-2 \%$ of the total and is localized primarily in the stroma of the chloroplast, although significant activity is also found in the cytoplasm of photosynthetic cells. ${ }^{180}$ The X-ray 3D structure of CA from Pisum sativum, pea (pdb 1EKJ) has been determined. ${ }^{181}$ The active site is located at the interface of two monomers with Cys160, His220 and Cys223 binding the catalytic $\mathrm{Zn}^{2+}$ ion. The fourth position is available for the binding of $\mathrm{H}_{2} \mathrm{O}$. The Thr199 residue acts as a hydrogen bond donor with respect to Glu106, and therefore allows only atoms capable of acting as hydrogen bond donors to bind to the $\mathrm{Zn}^{2+}$ ion with tetrahedral geometry. A narrow, hydrophilic channel that passes between Tyr205, Gln151, Gly224 and Asp162 is the only access to the active site of $\beta$-CA from bulk solvent. It is too narrow to allow the passage of anything larger than a water molecule, indicating the need for some sort of rearrangement in the course of the enzyme catalytic cycle. A model for $\beta$-CA catalysis has been proposed. ${ }^{181}$

\section{Zn-finger proteins}

The $\mathrm{Zn}$ element is a cofactor of the $\mathrm{Zn}$-finger proteins. These small proteins have a structural motif characterized by the coordination of one or more $\mathrm{Zn}$ that stabilize the fold. A small Zn-finger thylakoid membrane protein named Low Quantum Yield of Photosystem II_1 (LQY1) that shows disulfide isomerase activity has been identified. ${ }^{182}$ It is predicted to have a chloroplast transit peptide, a transmembrane domain, and a putative Zn-finger homologous to Escherichia coli DnaJ. The LQY1 protein interacts with the PSII core complex, and may act in the repair and reassembly cycle of the PSII-light-harvesting complex II (LHCII) supercomplex under high irradiance. Arabidopsis thaliana mutants lacking $L Q Y 1$ gene were found to have a reduced PSII electron transport rate, lower maximum PSII photochemical efficiency $\left(F_{\mathrm{v}} / F_{\mathrm{m}}\right)$ and higher non-photochemical quenching than wild-type plants as well as elevated accumulation of reactive oxygen species following high light treatment. They are more photoinhibited than wild-type control plants. ${ }^{183}$ After high light treatment, mutant plants also had less PSII-LHCII supercomplex than wild-type plants, indicating a defect in the repair mechanism under high light. LQY1 homologs were found in the genomes of numerous land plants, including angiosperms, gymnosperms, the bryophyte moss Physcomitrella, and the lycopod Selaginella, but not in cyanobacteria or algae, suggesting broad conservation of function in land plants.

\section{Zn transport pathways in chloroplast}

The HMA1 transporter, a member of the heavy metal-transporting ATPase family, which localizes to the chloroplast envelope, is able to transport $\mathrm{Zn}^{2+}$ besides $\mathrm{Cu}^{2+}$ (Fig. 1) ${ }^{56,57}$ In Arabidopsis thaliana, under conditions of excess $\mathrm{Zn}^{2+}$, AtHMA1 contributes to $\mathrm{Zn}^{2+}$ detoxification by reducing the $\mathrm{Zn}$ content of plastids.

\section{Transition metals and artificial photosynthesis}

Recent developments in the field of artificial photosynthesis have yielded the creation of an artificial leaf. ${ }^{184}$ The 'leaf' consists of a nickel-molybdenum-zinc (NiMoZn) compound on one side and a cobalt-phosphate cluster (COOEC) on the other side, with a sunlight collector in between. The latter mimics the structural and functional attributes of the oxygen-evolving core (OEC) complex of PSII. Similar to the OEC of PSII, the Co-OEC selfassembles upon oxidation of an earth-abundant metal ion from $2^{+}$to $3^{+}$, may operate in natural water at room temperature, and is self-healing. The Co-OEC also activates $\mathrm{H}_{2} \mathrm{O}$ by a proton-coupled electron transfer mechanism in which the Co-OEC is increased by four hole equivalents akin to the S-state pumping of the Kok cycle of PSII. X-ray absorption spectroscopy studies have established that the Co-OEC is a structural relative of $\mathrm{Mn}_{3} \mathrm{CaO}_{4}-\mathrm{Mn}$ cubane of the PSII, where Co replaces $\mathrm{Mn}$ and the cubane is extended in a corner-sharing, head-to-tail dimer. When the leaf is placed in water, hydrogen gas and oxygen gas are released from the $\mathrm{Ni}-\mathrm{Mo}-\mathrm{Zn}$ side and Co side, respectively, as the water is broken down into its components. The gases are then used in fuel cells to produce electricity. ${ }^{184,185}$

Single or mixed oxides of $\mathrm{Fe}$ and $\mathrm{Ni}$ have been examined as catalysts in photocatalytic water oxidation using $[\mathrm{Ru}(\mathrm{bpy})(3)]\left(2^{+}\right)$ as a photosensitizer and $\mathrm{S}_{2} \mathrm{O}_{8}{ }^{2-}$ as a sacrificial oxidant. The catalytic activity of nickel ferrite $\left(\mathrm{NiFe}_{2} \mathrm{O}_{4}\right)$ is comparable to that of previous catalysts containing Ir, $\mathrm{Ru}$, or Co in terms of $\mathrm{O}^{-2}$ yield and $\mathrm{O}^{-2}$ evolution rate under ambient reaction conditions. ${ }^{186}$ $\mathrm{NiFe}_{2} \mathrm{O}_{4}$ also possesses robustness and ferromagnetic properties, which are beneficial to easy recovery from the solution after reaction. Water oxidation catalysis achieved by a composite of earth-abundant elements will contribute to a new approach to the design of catalysts for artificial photosynthesis.

\section{Perspectives}

This review shows that the role of metals as redox cofactors in plant photosynthetic electron transport proteins and metalloenzymes is well established. The 3D structures of main redox photosynthetic metalloproteins have been resolved and progress has been made regarding the assembly of complexes and proteinprotein interactions (i.e., Fd:FNR, Fd:PSI, Pc:PSI complexes), 
but there are still unclear aspects. For instance, despite recent results in cyanobacteria that have provided new relevant insights the mechanism of water splitting catalyzed by the Mn-cluster and the exact functions of cyt $b_{559}$ and non-heme Fe in plant PSII need further investigations. Concerning proteins involved in chloroplast metal homeostasis noticeable effort has been done during the last decade. Several protein families have been identified that transport metals within this organelle but the complete homeostasis network is still unknown. For instance, the lack of information concerning $\mathrm{Mn}$ and $\mathrm{Zn}$ is greater than in the case of $\mathrm{Cu}$ and Fe. On the other hand, little is known about the 3D structure of metal transport proteins and the functional mechanism as well as their interactions. In plants, most of these investigations have been focused on gene expression and regulatory mechanisms but more information at a structural/functional level is needed. Some of these transporters are inserted in the membranes of chloroplast, either in the envelope membranes or in the thylakoid, making these structural studies more difficult. Further biochemical and structural investigations including molecular interactions and molecular recognition are necessary to know the molecular basis of this trafficking network. Some studies have been carried out in bacteria mainly those concerning $\mathrm{P}_{1 \mathrm{~B}}$-ATPase transporters, but they should be confirmed in plants.

Other aspect to be further explored is the molecular assembly mechanisms, in order to understand the nature of intermediate states during either self-assembly or the interaction between the apo-protein and proteins involved in metal cofactor insertion. The number of proteins identified being components of plastid Fe-S cluster assembly, the most abundant metal-cofactor in chloroplast, has increased in the last few years. The biosynthetic pathways for assembly are generally well known, but the molecular details of how metal cofactors are delivered from protein to protein are less well understood. The lack of studies addressing specific protein interactions, the conformation of intermediate states and dynamics in the assembly mechanism are noticeable. Such studies should also be extended to other metal-cofactors.

\section{Acknowledgements}

This work was supported by grants from Ministerio de Economía y Competitividad (ref. MAT2011-23861) and Gobierno de Aragón (ref. DGA-GC B18). All these grants were partially financed by the EU FEDER Program.

\section{References}

1 R. H. Holm, P. Kennepohl and E. I. Solomon, Structural and functional aspects of metals sites in biology, Chem. Rev., 1996, 96, 2239-2314.

2 A. G. Sykes, Advances in Inorganic Chemistry: Including Bioinorganic Studies, Gulf Professional Publishing, 2002, vol. 53, pp. 1-271.

3 E. I. Solomon and R. G. Hadt, Recent advances in understanding blue copper proteins, Coord. Chem. Rev., 2011, 255, 774-789.
4 S. Merchant and B. W. Dreyfuss, Posttranslational assembly of photosynthetic metalloproteins, Annu. Rev. Plant Physiol. Plant Mol. Biol., 1998, 49, 25-51.

5 M. M. Harding, The architecture of metal coordination groups in protein, Acta Crystallogr., Sect. D: Biol. Crystallogr., 2004, 60, 849-859.

6 I. Dokmanic, M. Sikic and S. Tomic, Metals in proteins: correlation between the metal-ion-type, coordination number and the aminoacid residues involved in the coordination, Acta Crystallogr., Sect. D: Biol. Crystallogr., 2008, 64, 257-263.

7 J. Balk and M. Pilon, Ancient and essential: the assembly of iron-sulfur clusters in plants, Trends Plant Sci., 2011, 16, 218-226.

8 J. A. Raven, M. C. W. Evans and R. E. Korb, The role of trace metals in photosynthetic electron transport in $\mathrm{O}_{2}$-evolving organisms, Photosynth. Res., 1999, 60, 111-149.

9 F. P. Molina-Heredia, J. Wastl, J. A. Navarro, D. S. Bendall, M. Hervás, C. J. Howe and M. A. De La Rosa, Photosynthesis: a new function for an old cytochrome?, Nature, 2003, 424, 33-34.

10 K. Sauer and V. K. Yachandra, A possible evolutionary origin for the $\mathrm{Mn}_{4}$ cluster of the photosynthetic water oxidation complex from natural $\mathrm{MnO}_{2}$ precipitates in the early ocean, Proc. Natl. Acad. Sci. U. S. A., 2002, 99, 8631-8636.

11 J. L. Burkhead, K. A. G. Reynolds, S. E. Abdel-Ghany, C. M. Cohu and M. Pilon, Copper homeostasis, New Phytol., 2009, 182, 799-816.

12 M. Pilon, C. M. Cohu, K. Ravet, S. E. Abdel-Ghany and F. Gaymard, Essential transition metal homeostasis in plants, Curr. Opin. Plant Biol., 2009, 12, 347-357.

13 I. Yruela, Copper in plants: acquisition, transport and interactions, Funct. Plant Biol., 2009, 36, 409-430.

14 C. Nouet, P. Motte and M. Hanikenne, Chloroplastic and mitochondrial metal homeostasis, Trends Plant Sci., 2011, 16, 395-404.

15 B. Hankamer, J. Barber and E. J. Boekema, Structure and membrane organization of photosystem II in green plants, Annu. Rev. Plant Physiol. Plant Mol. Biol., 1997, 48, 641-671.

16 I. R. Vassiliev, M. L. Antonkine and J. H. Golbeck, Ironsulfur clusters in type I reaction centers, Biochim. Biophys. Acta, 2001, 1507, 139-160.

17 B. A. Diner and F. Rappaport, Structure, dynamics and energetics of the primary photochemistry of photosystem II of oxygenic photosynthesis, Annu. Rev. Plant Biol., 2002, 53, 551-580.

18 N. Nelson and A. Ben-Shem, The complex architecture of oxygenic photosynthesis, Nat. Rev. Mol. Cell Biol., 2004, 6, 971-982.

19 T. Wydrzynski and K. Satoh, in Photosystem II: the lightdriven water:plastoquinone:oxidoreductase, ed. A. Govindjee, Advances in Photosynthesis and Respiration, Springer, Dordrecht, 2005, vol. 22.

20 E. Sárvári, Effects of Heavy Metals on Chlorophyll-Protein Complexes in Higher Plants: Causes and Consequences, 
in Handbook of Photosynthesis, ed. M. Pessarakli, CRC Press, Taylor \& Francis Group, LLC, 2005, 2nd edn, pp. 1-273.

21 N. Nelson and C. F. Yocum, Structure and Function of Photosystems I and II, Annu. Rev. Plant Biol., 2006, 57, 521-565.

22 G. Renger and T. Renger, Photosystem II: the machinery of photosynthetic water splitting, Photosynth. Res., 2008, 98, 53-80.

23 J. D. Rochaix, Regulation of photosynthetic electron transport, Biochim. Biophys. Acta, 2011, 1807, 375-383.

24 C. H. Foyer, J. Neukermans, G. Queval, G. Noctor and J. Harbinson, Photosynthetic control of electron transport and the regulation of gene expression, J. Exp. Bot., 2012, 63, 1637-1661.

25 T. Cardona, A. Sedoud, N. Cox and A. W. Rutherford, Charge separation in photosystem II: a comparative and evolutionary overview, Biochim. Biophys. Acta, 2012, 1817, 26-43.

26 A. Monari, T. Very, J.-L. Rivail and X. Assfeld, A QM/MM study on the spinach plastocyanin: redox properties and absorption spectra, Comput. Theor. Chem., 2012, 990, 119-125.

27 P. M. Kirwin, P. D. Elderfield and C. Robinson, Transport of proteins into chloroplasts. Partial purification of a thylakoidal processing peptidase involved in plastocyanin biogenesis, J. Biol. Chem., 1987, 262, 16386-16390.

28 S. E. Abdel-Ghany, Contribution of plastocyanin isoforms to photosynthesis and copper homeostasis in Arabidopsis thaliana grown at different copper regimes, Planta, 2009, 229, 767-779.

29 P. Pesaresia, M. Scharfenbergb, M. Weigelc, I. Granlundd, W. P. Schröderd, G. Finazzie, F. Rappaporte, S. Masierof, A. Furinig, P. Jahnsh and D. Leisterb, Mutants, overexpressors, and interactors of Arabidopsis plastocyanin isoforms: revised roles of plastocyanin in photosynthetic electron flow and thylakoid redox state, Mol. Plant, 2009, 2, 236-248.

30 F. Drepper, M. Hippler, W. Nitschke and W. Haehnel, Binding dynamics and electron transfer between plastocyanin and photosystem I, Biochemistry, 1996, 35, 1282-1295.

31 G. M. Soriano, M. V. Ponamarev, G. S. Tae and W. A. Cramer, Effect of the interdomain basic region of cytochrome $f$ on its redox reactions in vivo, Biochemistry, 1996, 35, 14590-14598.

32 A. B. Hope, Electron transfers amongst cytochrome $f$, plastocyanin and photosystem I: kinetics and mechanisms, Biochim. Biophys. Acta, 2000, 1456, 5-26.

33 Y. Xue, M. Okvist, O. Hansson and S. Young, Crystal structure of spinach plastocyanin at $1.7 \AA$ resolution, Protein Sci., 1998, 7, 2099-2105.

34 H. Sugawara, T. Inoue, C. Li, M. Gotowda, T. Hibino, T. Takabe and Y. Kai, Crystal structures of wild-type and mutant plastocyanins from a higher plant, Silene, J. Biochem., 1999, 125, 899-903.
35 F. Musiani, A. Dikiy, A. Y. Semenov and S. Ciurli, Structure of the Intermolecular Complex between Plastocyanin and Cytochrome $f$ from Spinach, J. Biol. Chem., 2005, 280, 18833-18841.

36 G. S. Kachalova, A. C. Shoshevac, G. P. Bourenkovd, A. A. Donchevc, M. I. Dimitrove and H. D. Bartunika, Structural comparison of the poplar plastocyanin isoforms PCa and PCb sheds new light on the role of the copper site geometry in interactions with redox partners in oxygenic photosynthesis, J. Inorg. Biochem., 2012, 115, 174-181.

37 K. N. Sas, A. Haldrup, L. Hemmingsen, E. Danielsen and L. H. Øgendal, pH-dependent structural change of reduced spinach plastocyanin studied by perturbed angular correlation of $\gamma$-rays and dynamic light scattering, J. Biol. Inorg. Chem., 2006, 11, 409-418.

38 I. Bertini, D. A. Bryant, S. Ciurli, A. Dikiy, C. O. Fernández, C. Luchinat, N. Safarov, A. J. Vila and J. Zhao, Backbone dynamics of plastocyanin in both oxidation states. Solution structure of the reduced form and comparison with the oxidized state, J. Biol. Chem., 2001, 276, 47217-47226.

39 W. Haehnel, A. Pröpper and H. Krause, Evidence for complexed plastocyanin as the immediate electron donor of P-700, Biochim. Biophys. Acta, 1980, 593, 384-399.

40 B. H. Lee, T. Hibino, T. Takabe, P. J. Weisbeek and T. Takabe, Site-directed mutagenetic study on the role of negative patches on Silene plastocyanin in the interactions with cytochrome $f$ and photosystem I, J. Biochem., 1995, 117, 1209-1221.

41 M. Hippler, J. Reichert, M. Sutter, E. Zak, L. Altschmied, U. Schröer, R. G. Herrmann and W. Haehnel, The plastocyanin binding domain of photosystem I, EMBO J., 1996, 15, 6374-6384.

42 K. Sigfridsson, S. Young and O. Hansson, Structural dynamics in the plastocyanin-photosystem I electron-transfer complex as revealed by mutant studies, Biochemistry, 1996, 35, 1249-1257.

43 K. Sigfridsson, S. Young and O. Hansson, Electron transfer between spinach plastocyanin mutants and photosystem I, Eur. J. Biochem., 1997, 245, 805-812.

44 S. Young, K. Sigfridsson, K. Olesen and O. Hansson, The involvement of the two acidic patches of spinach plastocyanin in the reaction with photosystem I, Biochim. Biophys. Acta, 1997, 1322, 106-114.

45 S. Modi, M. Nordling, L. G. Lundberg, O. Hansson and D. S. Bendall, Reactivity of cytochromes $c$ and $f$ with mutant forms of spinach plastocyanin, Biochim. Biophys. Acta, 1992, 1102, 85-90.

46 J. Illerhaus, L. Altschmied, J. Reichert, E. Zak, R. G. Herrmann and W. Haehnel, Dynamic interaction of plastocyanin with the cytochrome bf complex, J. Biol. Chem., 2000, 275, 17590-17595.

47 T. Ueda, N. Nomotoa, M. Koga, H. Ogasa, Y. Ogawa, M. Matsumotoa, P. Stampoulisa, K. Sodec, H. Terasawa and I. Shimada, Structural Basis of Efficient Electron Transport between Photosynthetic Membrane Proteins 
and Plastocyanin in Spinach Revealed Using Nuclear Magnetic Resonance, Plant Cell, 2012, 24, 4173-4186.

48 D. Farkas and Ö. Hansson, An NMR study elucidating the binding of $\mathrm{Mg}$ (II) and $\mathrm{Mn}$ (II) to spinach plastocyanin. Regulation of the binding of plastocyanin to subunit PsaF of photosystem I, Biochim. Biophys. Acta, 2011, 1807, 1539-1548.

49 J. M. Argüello, E. Eren and M. González-Guerrero, The structure and function of heavy metal transport P1BATPases, Biometals, 2007, 20, 233-248.

50 M. González-Guerrero and J. M. Argüello, Mechanism of $\mathrm{Cu}^{+}$-transporting ATPases: soluble $\mathrm{Cu}^{+}$chaperones directly transfer $\mathrm{Cu}^{+}$to transmembrane transport sites, Proc. Natl. Acad. Sci. U. S. A., 2008, 105, 5992-5997.

51 A. C. Rosenzweig and J. M. Argüello, Toward a molecular understanding of metal transport by P1B-Type ATPases, Curr. Top. Membr., 2012, 69, 113-136.

52 W. Tapken, K. Ravet and M. Pilon, Plastocyanin controls the stabilization of the thylakoid Cu-transporting P-type ATPase PAA2/HMA8 in response to low copper in Arabidopsis, J. Biol. Chem., 2012, 287, 18544-18550.

53 S. E. Abdel-Ghany, P. Müller-Moulé, K. K. Niyogi, M. Pilon and T. Shikanai, Two P-type ATPases are required for copper delivery in Arabidopsis thaliana chloroplasts, Plant Cell, 2005, 17, 1233-1251.

54 S. Shcolnick and N. Keren, Metal homeostasis in cyanobacteria and chloroplasts. Balancing benefits and risks to the photosynthetic apparatus, Plant Physiol., 2006, 141, 805-810.

55 D. Seigneurin-Berny, A. Gravot, P. Auroy, C. Mazard, A. Kraut, G. Finazzi, D. Grunwald, F. Rappaport, A. Vavasseur, J. Joyard, P. Richaud and N. Rolland, HMA1, a new Cu-ATPase of the chloroplast envelope, is essential for growth under adverse light conditions, J. Biol. Chem., 2006, 281, 2882-2892.

56 Y. Y. Kim, H. Choi, S. Segami, H. T. Cho, E. Martinoia, M. Maeshima and Y. Lee, AtHMA1 contributes to the detoxification of excess $\mathrm{Zn}(\mathrm{II})$ in Arabidopsis, Plant J., 2009, 58, 737-753.

57 M. D. Mikkelsen, P. Pedas, M. Schiller, E. Vincze, R. F. Mills, S. Borg, A. Møller, J. K. Schjoerring, L. E. Williams, L. Baekgaard, P. B. Holm and M. G. Palmgren, Barley HvHMA1 is a heavy metal pump involved in mobilizing organellar $\mathrm{Zn}$ and $\mathrm{Cu}$ and plays a role in metal loading into grains, PLoS One, 2012, 7, e49027.

58 S. Sagasti, I. Yruela, M. Bernal, M. A. Luján, S. Frago, M. Medina and R. Picorel, Characterization of the recombinant copper chaperone (CCS) from the plant Glycine (G.) max, Metallomics, 2011, 3, 169-175.

59 G. S. Waldo, E. Wright, Z. H. Whang, J. F. Briat, E. C. Theil and D. E. Sayers, Formation of the ferritin iron mineral occurs in plastids, Plant Physiol., 1995, 109, 797-802.

60 J. F. Briat, K. Ravet, N. Arnaud, C. Duc, J. Boucherez, B. Touraine, F. Cellier and F. Gaymard, New insights into ferritin synthesis and function highlight a link between iron homeostasis and oxidative stress in plants, Ann. Bot., 2010, 105, 811-822.

61 A. Ben-Shem, F. Frolow and N. Nelson, Crystal structure of plant photosystem I, Nature, 2003, 426, 630-635.

62 A. Amunts, O. Drory and N. Nelson, The structure of a plant photosystem I supercomplex at $3.4 \AA$ resolution, Nature, 2007, 447, 58-63.

63 A. Amunts, H. Toporik, A. Borovikova and N. Nelson, Structure determination and improved model of plant photosystem I, J. Biol. Chem., 2010, 285, 3478-3486.

64 P. E. Jensen, R. Bassi, E. J. Boekema, J. P. Dekker, S. Jansson, D. Leister, C. Robinson and H. V. Scheller, Structure, function and regulation of plant photosystem I, Biochim. Biophys. Acta, 2007, 1767, 335-352.

65 A. Amunts and N. Nelson, Plant photosystem I design in the light of evolution, Structure, 2009, 17, 637-650.

66 C. Jolley, A. Ben-Shem, N. Nelson and P. Fromme, Structure of plant photosystem I revealed by theoretical modelling, J. Biol. Chem., 2005, 280, 33627-33636.

67 M. A. Schöttler, C. A. Albus and R. Bock, Photosystem I: its biogenesis and function in higher plants, J. Plant Physiol., 2011, 168, 1452-1461.

68 A. Bush and M. Hippler, The structure and function of eukaryotic photosystem I, Biochim. Biophys. Acta, 2011, 1807, 864-877.

69 N. Nelson and A. Ben-Shem, Photosystem I reaction center: past and future, Photosynth. Res., 2002, 73, 193-206.

70 T. Shikanai, Cyclic electron transport around photosystem I: genetic approaches, Annu. Rev. Plant Biol., 2007, 58, 199-217.

71 M. L. Antonkine, P. Jordan, P. Fromme, N. Krauß, J. H. Golbeck and D. Stehlik, Assembly of protein subunits within the stromal ridge of photosystem I structural changes between unbound and sequentially PSI-bound polypeptides and correlated changes of the magnetic properties of the terminal iron sulphur clusters, J. Mol. Biol., 2003, 327, 671-697.

72 K. Ali, S. Santabarbara, P. Heathcote, M. C. Evans and S. Purton, Bidirectional electron transfer in photosystem I: replacement of the symmetry-breaking tryptophan close to the PsaB-bound phylloquinone $\mathrm{A}_{1 \mathrm{~B}}$ with a glycine residue alters the redox properties of $\mathrm{A}_{1 \mathrm{~B}}$ and blocks forward electron transfer at cryogenic temperatures, Biochim. Biophys. Acta, 2006, 1757, 1623-1633.

73 S. Santabarbara, I. Kuprov, P. J. Hore, A. Casal, P. Heathcote and M. C. Evans, Analysis of the spinpolarized electron spin echo of the $\left[\mathrm{P}_{700}+\mathrm{A}_{1}{ }^{-}\right]$radical pair of photosystem I indicates that both reaction center subunits are competent in electron transfer in cyanobacteria, green algae, and higher plants, Biochemistry, 2006, 45, 7389-7403.

74 S. Santabarbara, P. Heathcote and M. C. Evans, Modelling of the electron transfer reactions in photosystem I by electron tunnelling theory: the phylloquinones bound to the PsaA and the PsaB reaction centre subunits of PS I are almost isoenergetic to the iron-sulfur cluster $\mathrm{F}(\mathrm{X})$, Biochim. Biophys. Acta, 2005, 1708, 283-310. 
75 N. Srinivasan, S. Santabarbara, F. Rappaport, D. Carbonera, K. Redding, A. van der Est and J. H. Golbeck, J. Phys. Chem. $B, 2011,115,1751-1759$.

76 P. Fromme, H. Bottin, N. Krauss and P. Sétif, Crystallization and electron paramagnetic resonance characterization of the complex of photosystem I with its natural electron acceptor ferredoxin, Biophys. J., 2002, 83, 1760-1773.

77 M. C. W. Evans, C. K. Sihra, J. R. Bolton and R. Cammack, Primary electron acceptor complex of photosystem I in spinach chloroplasts, Nature, 1975, 256, 668-670.

78 T. Berthold, E. D. von Gromoff, S. Santabarbara, P. Stehle, G. Link, O. G. Poluektov, P. Heathcote, C. F. Beck, M. C. Thurnauer and G. Kothe, Exploring the electron transfer pathways in photosystem I by observation of the B-side radical pair $\mathrm{P}_{700}(+) \mathrm{A}_{1 \mathrm{~B}}(-)$ in whole cells of the deuterated green alga Chlamydomonas reinhardtii at cryogenic temperatures, J. Am. Chem. Soc., 2012, 134, 5563-5576.

79 B. Jagannathan, S. Dekat, J. H. Golbeck and K. V. Lakshmi, The assembly of a multisubunit photosynthetic membrane protein complex: a site-specific spin labeling EPR spectroscopic study of the PsaC subunit in photosystem I, Biochemistry, 2010, 49, 2398-2408.

80 K. N. Ferreira, T. M. Iverson, K. Maghlaoui, J. Barber and S. Iwata, Architecture of the photosynthetic oxygenevolving center, Science, 2004, 303, 1831-1838.

81 B. Loll, J. Kern, W. Saenger, A. Zouni and J. Biesiadka, Towards complete cofactor arrangement in the $3.0 \AA$ resolution crystal structure of photosystem II, Nature, 2005, 438, 1040-1044.

82 R. Hienerwadel and C. Berthomieu, Bicarbonate binding to the non-heme iron of photosystem II, investigated by Fourier transform infrared difference spectroscopy and 13C-labeled bicarbonate, Biochemistry, 1995, 34, 16288-16297.

83 A. Guskov, J. Kern, A. Gabdulkhakov, M. Broser, A. Zouni and W. Saenger, Cyanobacterial photosystem II at $2.9 \AA$ resolution and the role of quinones, lipids, channels and chloride, Nat. Struct. Mol. Biol., 2009, 16, 334-342.

84 Y. Umena, K. Kawakami, J.-R. Shen and N. Kamiya, Crystal structure of oxygen-evolving photosystem II at a resolution of $1.9 \AA$, Nature, 2011, 473, 55-60.

$85 \mathrm{H}$. Ishikita and E. Knapp, Oxidation of the non-heme iron complex in photosystem II, Biochemistry, 2005, 44, 14772-14783.

86 J. P. McEvoy and G. W. Brudvig, Redox reactions of the non-heme iron in photosystem II: an EPR spectroscopic study, Biochemistry, 2008, 47, 13394-13403.

87 N. Cox, L. Jin, A. Jaszewski, P. J. Smith, E. Krausz, A. W. Rutherford and R. Pace, The semiquinone-iron complex of photosystem II: structural insights from ESR and theoretical simulation; evidence that the native ligand to the non-heme iron is carbonate, Biophys. J., 2009, 97, 2024-2033.

88 R. Takahashi, A. Boussac, M. Sugiura and T. Noguchi, Structural coupling of a tyrosine side chain with the non-heme iron center in photosystem II as revealed by light-induced Fourier transform infrared difference spectroscopy, Biochemistry, 2009, 48, 8994-9001.

89 R. G. Herrmann, J. Alt, B. Schiller, W. R. Widger and W. A. Cramer, Nucleotide sequence of the gene for apocytochrome $b-559$ on the spinach plastid chromosome: implications for the structure of the membrane protein, FEBS Lett., 1984, 176, 239-244.

90 W. R. Widger, W. A. Cramer, M. Hermodson and R. G. Herrmann, Evidence for a hetero-oligomeric structure of the chloroplast cytochrome b-559, FEBS Lett., 1985, 191, 186-190.

91 G. T. Babcock, W. R. Widger, W. A. Cramer, W. A. Oertling and J. G. Metz, Axial ligands of chloroplast cytochrome $b$-559-identification and requirement for a haemcrosslinked polypeptide structure, Biochemistry, 1985, 24, 3638-3645.

92 G. S. Tae, M. T. Black, W. A. Cramer, O. Vallon and L. Bogorad, Thylakoid membrane protein topography: transmembrane orientation of the chloroplast cytochrome b-559 psbE gene product, Biochemistry, 1988, 27, 9075-9080.

93 J. Whitmarsh and H. B. Pakrasi, Form and function of cytochrome b-559, in Oxygenic Photosynthesis: The Light Reactions, ed. D. R. Ort and C. Yocum, Kluwer Academic Publishers, Dordrecht, The Netherlands, 1996, pp. 249-264.

94 D. H. Stewart and G. W. Brudvig, Cytochrome $b_{559}$ of photosystem II, Biochim. Biophys. Acta, 1998, 1367, 63-87.

95 J. M. Ortega, M. Hervás and M. Losada, Redox and acidbase characterization of cytochrome $b$-559 in photosystem II particles, Eur. J. Biochem., 1988, 171, 449-455.

96 M. Roncel, J. M. Ortega and M. Losada, Factors determining the special redox properties of photosynthetic cytochrome $b_{559}$, Eur. J. Biochem., 2001, 268, 4961-4968.

97 M. A. Luján, J. I. Martínez, P. J. Alonso, F. Guerrero, M. Roncel, J. M. Ortega, I. Yruela and R. Picorel, Reconstitution, spectroscopy, and redox properties of the photosynthetic recombinant cytochrome $b_{559}$ from higher plants, Photosynth. Res., 2012, 112, 193-204.

98 O. Kaminskaya, V. A. Shuvalov and G. Renger, Evidence for a novel quinone-binding site in the photosystem II (PS II) complex that regulates the redox potential of cytochrome $b_{559}$, Biochemistry, 2007, 46, 1091-1105.

99 T. Shibamoto, Y. Kato and T. Watanabe, Spectroelectrochemistry of cytochrome $b_{559}$ in the D1-D2-Cyt $b_{559}$ complex from spinach, FEBS Lett., 2008, 582, 1490-1494.

100 U. Heber, M. R. Kirk and N. K. Boardman, Photoreactions of cytochrome $b$-559 and cyclic electron flow in photosystem II of intact chloroplasts, Biochim. Biophys. Acta, 1979, 546, 292-306.

101 L. K. Thompson and G. W. Brudwig, Cytochrome b-559 may function to protect photosystem II from photoinhibition, Biochemistry, 1988, 27, 6653-6658.

102 O. Canaani and M. Havaux, Evidence for a biological role in photosynthesis for cytochrome $b$-559-a component of 
photosystem II reaction center, Proc. Natl. Acad. Sci. U. S. A., 1990, 87, 9295-9299.

103 D. B. Knaff and D. I. Arnon, Light-induced oxidation of a chloroplast $b$-type cytochrome at $-189{ }^{\circ} \mathrm{C}$, Proc. Natl. Acad. Sci. U. S. A., 1969, 63, 956-962.

104 R. A. Floyd, B. Chance and D. De Vault, Low-temperature photoinduced reactions in green leaves chloroplasts, Biochim. Biophys. Acta, 1971, 226, 103-112.

105 G. Ben-Hayyim, On the photooxidation of a high potential form of cytochrome b-559, FEBS Lett., 1972, 28, 145-148.

106 C. A. Buser, L. K. Thompson, B. A. Diner and G. W. Brudwig, Electron-transfer reactions in manganesedepleted photosystem II, Biochemistry, 1990, 29, 8977-8985.

107 O. Kaminskaya, G. Renger and V. A. Shuvalov, Effect of dehydration on light-induced reactions in photosystem II: photoreactions of cytochrome $b_{559}$, Biochemistry, 2003, 42, 8119-8132.

108 O. P. Kaminskaya and V. A. Shuvalov, Biphasic reduction of cytochrome $b_{559}$ by plastoquinol in photosystem II membrane fragments: evidence for two types of cytochrome $b_{559}$ /plastoquinone redox equilibria, Biochim. Biophys. Acta, 2013, 1827, 471-483.

109 I. Yruela, I. García-Rubio, M. Roncel, J. I. Martínez, M. V. Ramiro, J. M. Ortega, P. J. Alonso and R. Picorel, Detergent effect on cytochrome $b_{559}$ electron paramagnetic resonance signals in the photosystem II reaction centre, Photochem. Photobiol. Sci., 2003, 2, 437-442.

110 I. García-Rubio, J. I. Martínez, R. Picorel, I. Yruela and P. J. Alonso, HYSCORE spectroscopy in the cytochrome $b_{559}$ of photosystem II reaction centre, J. Am. Chem. Soc., 2003, 125, 15846-15854.

111 P. Pospíšil, Enzymatic function of cytochrome $b_{559}$ in photosystem II, J. Photochem. Photobiol., B, 2011, 104, 341-347.

112 J. F. Allen, Cytochrome $b_{6} f$ : structure for signalling and vectorial metabolism, Trends Plant Sci., 2004, 9, 130-137.

113 H. Zhang, J. P. Whitelegge and W. A. Cramer, Flavonucleotide:ferredoxin reductase is a subunit of the plant cytochrome $b_{6} f$ complex, J. Biol. Chem., 2001, 276, 38159-38165.

114 C. de Vitry, C. Breyton, Y. Pierre and J. L. Popot, The 4 kDa nuclear-encoded PetM polypeptide of the chloroplast cytochrome $b_{6} f$ complex, J. Biol. Chem., 1996, 271, 10667-10671.

115 W. A. Cramer, J. Yan, H. Zhang, G. Kurisu and J. L. Smith, Structure of the cytochrome $b_{6} f$ complex: new prosthetic groups, Q-space, and the 'hors d'oeuvres hypothesis' for assembly of the complex, Photosynth. Res., 2005, 851, 133-143.

116 D. Maiwald, A. Dietzmann, P. Jahns, P. Pesaresi, P. Joliot, A. Joliot, J. Z. Levin, F. Salamini and D. Leister, Knock-out of the genes coding for the Rieske protein and the ATPsynthase delta-subunit of Arabidopsis. Effects on photosynthesis, thylakoid protein composition, and nuclear chloroplast gene expression, Plant Physiol., 2003, 133, 191-202.

117 D. Stroebel, Y. Choquet, J. L. Popot and D. Picot, An atypical haem in the cytochrome $b(6) f$ complex, Nature, 2003, 426, 413-418.

118 G. Kurisu, H. Zhang, J. L. Smith and W. A. Cramer, Structure of the cytochrome $b_{6} f$ complex of oxygenic photosynthesis: tuning the cavity, Science, 2003, 302, 1009-1014.

119 B. Gubernator, J. Kroliczewski, T. Kallas and A. Szczepaniak, Iron-sulfur cluster reconstitution of spinach chloroplast Rieske protein requires a partially prefolded apoprotein, Biochim. Biophys. Acta, Proteins Proteomics, 2005, 1764, 735-742.

120 W. Nitschke and G. Hauska, On the nature of the $g=6$ EPR signal in isolated cytochrome $b_{6} f$ complex from spinach chloroplasts, Biochim. Biophys. Acta, 1987, 892, 314-319.

121 R. D. Britt, K. Sauer, M. P. Klein, D. B. Knaff, A. Kriauciunas, C. A. Yu, L. Yu and R. Malkin, Electronspin echo envelope modulation spectroscopy supports the suggested coordination of 2 histidine ligands to the Rieske $\mathrm{Fe}-\mathrm{S}$ centers of the cytochrome- $b_{6} f$ complex of spinach and the cytochrome-bc1 complexes of Rhodospirillum rubrumRhodobacter sphaeroides r-26, and bovine heartmitochondria, Biochemistry, 1991, 30, 1892-1901.

122 P. Jäger-Vottero, A.-J. Dorne, J. Jordanov, R. Douce and J. Joyard, Redox chains in chloroplast envelope membranes: spectroscopic evidence for the presence of electron carriers, including iron-sulfur centers, Proc. Natl. Acad. Sci. U. S. A., 1997, 94, 1597-1602.

123 V. Schünemann, A. X. Trautwein, J. Illerhaus and W. Haehnel, Mössbauer and electron paramagnetic resonance studies of the cytochrome $b f$ complex, Biochemistry, 1999, 38, 8981-8991.

124 A. I. Zatsman, H. Zhang, W. A. Gunderson, W. A. Cramer and M. P. Hendrich, Heme-Heme Interactions in the Cytochrome $b_{6} f$ Complex: EPR Spectroscopy and Correlation with Structure, J. Am. Chem. Soc., 2006, 128, 14246-14247.

125 R. Cammack and F. MacMillan, Electron magnetic resonance of iron-sulfur proteins in electron-transfer chains: resolving complexity, in Metals in Biology: Applications of high-resolution EPR to metalloenzymes, ed. G. Hanson and L. Berliner, Springer Science, Biological Magnetic Resonance, 2010, vol. 29.

126 H. M. Li, S. M. Theg, C. M. Bauerle and K. Keegstra, Metalion-center assembly of ferredoxin and plastocyanin in isolated chloroplasts, Proc. Natl. Acad. Sci. U. S. A., 1990, 87, 6748-6752.

127 S. Suzuki, K. Izumihara and T. Hase, Plastid import and iron-sulfur cluster assembly of photosynthetic and nonphotosynthetic ferredoxin isoproteins in maize, Plant Physiol., 1991, 97, 375-380.

128 M. Pilon, B. de Kruijff and P. J. Weisbeek, New insights into the import mechanism of the ferredoxin precursor into chloroplasts, J. Biol. Chem., 1992, 267, 2548-2556. 
129 G. Hanke and P. Mulo, Plant type ferredoxins and ferredoxin-dependent metabolism, Plant, Cell Environ., 2012, 36, 1071-1084.

130 D. B. Knaff and M. Hirasawa, Ferredoxin-dependent chloroplast enzymes, Biochim. Biophys. Acta, 1991, 1056, 93-125.

131 I. Voss, T. Goss, E. Murozuka, B. Altmann, K. J. McLean, S. E. Rigby, A. W. Munro, R. Scheibe, T. Hase and G. T. Hanke, FdC1, a novel ferredoxin protein capable of alternative electron partitioning, increases in conditions of acceptor limitation at photosystem I, J. Biol. Chem., 2011, 286, 50-59.

132 K. Fukuyama, T. Hase, S. Matsumoto, T. Tsukihara, Y. Katsube, N. Tanaka, M. Kakudo, K. Wada and H. Matsubara, Structure of S. platensis [2Fe-2S] ferredoxin and evolution of chloroplast-type ferredoxins, Nature, 1980, 286, 522-524.

133 P. A. Bruns and C. M. Karplus, Refined crystal-structure of spinach ferredoxin reductase at $1.7 \AA$ resolution - oxidized, reduced and 2'-phospho-5'-AMP bound-states, J. Mol. Biol., 1995, 247, 125-145.

134 K. Fukuyama, N. Ueki, H. Nakamura, T. Tsukihara and H. Matsubara, Tertiary structure of $[2 \mathrm{Fe}-2 \mathrm{~S}]$ ferredoxin from Spirulina platensis refined at $2.5 \AA$ resolution: structural comparisons of plant-type ferredoxins and an electrostatic potential analysis, J. Biochem., 1995, 117, 1017-1023.

135 A. Dorowski, A. Hofmann, C. Steegborn, M. Boicu and R. Huber, Crystal structure of paprika ferredoxin-NADP ${ }^{+}$ reductase. Implications for the electron transfer pathway, J. Biol. Chem., 2001, 276, 9253-9263.

136 H. Botti, M. A. Musumeci, E. A. Ceccarelli and A. Buschiazzo, Swapping Fad Binding Motifs between Plastidic and Bacterial Ferredoxin-Nadp $(\mathrm{H})$ Reductases, Biochemistry, 2011, 50, 2111-2122.

137 H. Kameda, K. Hirabayashi, K. Wada and K. Fukuyama, Mapping of protein-protein interaction sites in the plant-type [2Fe-2S] ferredoxin, Plos One, 2011, 6, e21947.

138 N. Carrillo and E. A. Ceccarelli, Open questions in ferredoxin-NADP ${ }^{+}$reductase catalytic mechanism, Eur. J. Biochem., 2003, 270, 1900-1915.

139 E. A. Ceccarelli, A. K. Arakaki, N. Cortez and N. Carrillo, Functional plasticity and catalytic efficiency in plant and bacterial ferredoxin-NADP $(\mathrm{H})$ reductases, Biochim. Biophys. Acta, 2004, 1698, 155-165.

140 M. Medina, Structural and mechanistic aspects of flavoproteins: photosynthetic electron transfer from photosys-

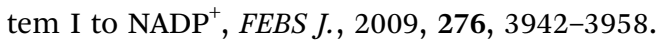

141 G. Kurisu, M. Kusunoki, E. Katoh, T. Yamazaki, K. Teshima, Y. Onda, Y. Kimata-Ariga and T. Hase, Structure of the electron transfer complex between ferredoxin and ferredoxin-NADP $(+)$ reductase, Nat. Struct. Biol., 2001, 8, 117-121.

142 J. Jeong, C. Cohu, L. Kerkeb, M. Pilon, E. L. Connolly and M. L. Guerinot, Chloroplast Fe(III) chelate reductase activity is essential for seedling viability under iron limiting conditions, Proc. Natl. Acad. Sci. U. S. A., 2008, 105, 10619-10624.

143 S. Conte, D. Stevenson, I. Furner and A. Lloyd, Multiple antibiotic resistance in Arabidopsis is conferred by mutations in a chloroplast-localized transport protein, Plant Physiol., 2009, 151, 559-573.

144 D. Duy, R. Stübe, G. Wanner and K. Philippar, The Chloroplast Permease PIC1 Regulates Plant Growth and Development by Directing Homeostasis and Transport of Iron1, Plant Physiol., 2011, 155, 1709-1722.

145 E. Shimoni-Shor, M. Hassidim, N. Yuval-Naeh and N. Keren, Disruption of Nap14, a plastid-localized nonintrinsic ABC protein in Arabidopsis thaliana results in the over-accumulation of transition metals and in aberrant chloroplast structures, Plant, Cell Environ., 2010, 33, 1029-1038.

146 D. C. Johnson, D. R. Dean, A. D. Smith and M. K. Johnson, Structure, function, and formation of biological ironsulfur clusters, Annu. Rev. Biochem., 2005, 74, 247-281.

147 S. Léon, B. Touraine, J. F. Briat and S. Lobréaux, The AtNFS2 gene from Arabidopsis thaliana encodes a NifS-like plastidial cysteine desulphurase, Biochem. J., 2002, 366, 557-564.

148 E. A. Pilon-Smits, G. F. Garifullina, S. Abdel-Ghany, S. Kato, H. Mihara, K. L. Hale, J. L. Burkhead, N. Esaki, T. Kurihara and M. Pilon, Characterization of a NifS-like chloroplast protein from Arabidopsis. Implications for its role in sulfur and selenium metabolism, Plant Physiol., 2002, 130, 1309-1318.

149 X. M. Xu, S. Adams, N. H. Chua and S. G. Møller, AtNAP1 represents an atypical SufB protein in Arabidopsis plastids, J. Biol. Chem., 2005, 280, 6648-6654.

150 K. Nishio and M. Nakai M, Transfer of iron-sulphur cluster from NifU to apoferredoxin, J. Biol. Chem., 2000, 275, 22615-22618.

151 T. Yabe, E. Yamashita, A. Kikuchi, K. Morimoto, A. Nakagawa, T. Tsukihara and M. Nakai, Structural analysis of Arabidopsis CnfU protein: an iron-sulfur cluster biosynthetic scaffold in chloroplasts, J. Mol. Biol., 2008, 381, 160-173.

152 L. Lezhneva, K. Amann and J. Meurer, The universally conserved HCF101 protein is involved in assembly of [4Fe-4S]-cluster-containing complexes in Arabidopsis thaliana chloroplasts, Plant J., 2004, 37, 174-185.

153 J. Stöckel and R. J. Oelmüller, A novel protein for photosystem I biogenesis, J. Biol. Chem., 2004, 279, 10243-10251.

154 S. Schwenkert, J. Legen, T. Takami, T. Shikanai, R. G. Herrmann and J. Meurer, Role of the low-molecular-weight subunits PetL, PetG, and PetN in assembly, stability, and dimerization of the cytochrome $b_{6} f$ complex in tobacco, Plant Physiol., 2007, 144, 1924-1935.

155 P. Mulo, S. Sirpiö, M. Suorsa and E. M. Aro, Auxiliary proteins involved in the assembly and sustenance of photosystem II, Photosynth. Res., 2008, 98, 489-501.

156 J. Liu, H. Yang, Q. Lu, X. Wen, F. Chen, L. Peng, L. Zhang and C. Lua, PSBP-DOMAIN PROTEIN1, a Nuclear-Encoded 
Thylakoid Lumenal Protein, Is Essential for Photosystem I Assembly in Arabidopsis, Plant Cell, 2012, 24, 4992-5006.

157 K. Motohashi and T. Hisabori, HCF164 receives reducing equivalents from stromal thioredoxin across the thylakoid membrane and mediates reduction of target proteins in the thylakoid lumen, J. Biol. Chem., 2006, 281, 35039-35047.

158 K. Lennartz, H. Plücken, A. Seidler, P. Westhoff, N. Bechtold and K. Meierhoff, HCF164 Encodes a Thioredoxin-Like Protein Involved in the Biogenesis of the Cytochrome $b_{6} f$ Complex in Arabidopsis, Plant Cell, 2001, 13, 2539-2552.

159 D. Lyska, S. Paradies, K. Meierhoff and P. Westhoff, HCF208, a homolog of Chlamydomonas CCB2, is required for accumulation of native cytochrome $b 6$ in Arabidopsis thaliana, Plant Cell Physiol., 2007, 48, 1737-1746.

160 L. Lezhneva, R. Kuras, G. Ephritikhine and C. de Vitry, A Novel Pathway of Cytochrome $c$ Biogenesis Is Involved in the Assembly of the Cytochrome $b_{6} f$ Complex in Arabidopsis Chloroplasts, J. Biol. Chem., 2008, 283, 24608-24616.

161 C. de Vitry, Cytochrome $c$ maturation system on the negative side of bioenergetic membranes: CCB or System IV, FEBS J., 2011, 278, 4189-4197.

$162 \mathrm{~J}$. Yano and V. K. Yachandra, Where water is oxidized to dioxygen: structure of the photosynthetic $\mathrm{Mn}_{4} \mathrm{Ca}$ cluster from X-ray spectroscopy, Inorg. Chem., 2008, 47, 1711-1726.

163 L. V. Kulik, B. Epel, W. Lubitz and J. Messinger, Electronic Structure of the $\mathrm{Mn}_{4} \mathrm{O}_{x}$ Ca cluster in the $\mathrm{S}_{0}$ and $\mathrm{S}_{2}$ States of the Oxygen-Evolving Complex of Photosystem II Based on Pulse 55Mn-ENDOR Spectroscopy, J. Am. Chem. Soc., 2007, 129, 13421-13435.

164 E. M. Sproviero, J. P. McEvoy, J. A. Gascón, G. W. Brudvig and V. S. Batista, A Model of the Oxygen Evolving Center of Photosystem II Predicted by Structural Refinement Based on EXAFS Simulations, J. Am. Chem. Soc., 2008, 130, 6728-6730.

$165 \mathrm{~J}$. Barber and J. W. Murray, The structure of the $\mathrm{Mn}_{4} \mathrm{Ca}_{2}+$ cluster of photosystem II and its protein environment as revealed by X-ray crystallography, Philos. Trans. R. Soc., B, 2008, 363, 1129-1138.

166 S. Zein, L. V. Kulik, J. Yano, J. Kern, Y. Pushkar, A. Zouni, V. K. Yachandra, W. Lubitz, F. Neese and J. Messinger, Focusing the view on nature's water-splitting catalyst, Philos. Trans. R. Soc. London, Ser. B, 2008, 363, 1167-1177.

167 J. I. Martínez, I. Yruela, R. Picorel and P. J. Alonso, H-1 Hyperfine Interactions in the Mn-Cluster of Photosystem II in the S-2 State Detected by Hyperfine SublevelCorrelation Spectroscopy, J. Phys. Chem. B, 2010, 114, 15345-15353.

168 L. Rapatskiy, N. Cox, A. Savitsky, W. M. Ames, J. Sander, M. M. Nowaczyk, M. Rogner, A. Boussac, F. Neese, J. Messinger and W. Lubitz, Detection of the water-binding sites of the oxygen-evolving complex of photosystem II using W-band O-17 electron-electron double resonancedetected NMR spectroscopy, J. Am. Chem. Soc., 2012, 134, 16619-16634.
169 A. Galstyan, A. Robertazzi and E. W. Knapp, Oxygen-evolving Mn cluster in photosystem II: the protonation pattern and oxidation state in the high-resolution crystal structure, J. Am. Chem. Soc., 2012, 134, 7442-7449.

170 W. Ames, D. A. Pantazis, V. Krewald, N. Cox, J. Messinger, W. Lubitz and F. Neese, Theoretical evaluation of structural models of the $\mathrm{S}_{2}$ state in the oxygen evolving complex of photosystem II: protonation states and magnetic interactions, J. Am. Chem. Soc., 2011, 133, 19743-19757.

171 J. S. Kanady, J. L. Mendoza-Cortes, E. Y. Tsui, R. J. Nielsen, W. A. Goddard and T. Agapie, Oxygen atom transfer and oxidative water incorporation in cuboidal $\mathrm{Mn}_{3} \mathrm{MO}_{n}$, complexes based on synthetic, isotopic labeling, and computational studies, J. Am. Chem. Soc., 2013, 135, 1073-1082.

172 F. H. M. Kouaa, Y. Umenab, K. Kawakamic and J.-R. Shen, Structure of Sr-substituted photosystem II at $2.1 \AA$ resolution and its implications in the mechanism of water oxidation, Proc. Natl. Acad. Sci. U. S. A., 2013, 110, 3889-3894.

173 H. Liu, R. Y. Huang, J. Chen, M. L. Gross and H. B. Pakrasi, Psb27, a transiently associated protein, binds to the chlorophyll binding protein CP43 in photosystem II assembly intermediates, Proc. Natl. Acad. Sci. U. S. A., 2011, 108, 18536-18541.

174 F. Michoux, K. Takasaka, M. Boehm, J. Komenda, P. J. Nixon and J. W. Murray, Crystal structure of the Psb27 assembly factor at 1.6 A: implications for binding to photosystem II, Photosynth. Res., 2012, 110, 169-175.

175 K. Ido, S. Kakiuchi, C. Uno, T. Nishimura, Y. Fukao, T. Noguchi, F. Sato and K. Ifuku, The conserved His-144 in the PsbP protein is important for the interaction between the PsbP N-terminus and the cyt $b_{559}$ subunit of photosystem II, J. Biol. Chem., 2012, 287, 26377-26387.

176 S. Kakiuchi, C. Uno, K. Ido, T. Nishimura, T. Noguchi, K. Ifuku and F. Sato, The PsbQ protein stabilizes the functional binding of the PsbP protein to photosystem II in higher plants, Biochim. Biophys. Acta, 2012, 1817, 1346-1351.

177 J. K. Pittman, Managing the manganese: molecular mechanisms of manganese transport and homeostasis, New Phytol., 2005, 167, 733-742.

178 V. Lanquar, M. S. Ramos, F. Lelièvre, H. Barbier-Brygoo, A. Krieger-Liszkay, U. Krämer and S. Thomine, Export of vacuolar manganese by AtNRAMP3 and AtNRAMP4 is required for optimal photosynthesis and growth under manganese deficiency, Plant Physiol., 2010, 152, 1986-1999.

179 V. V. Bartsevich and H. B. Pakrasi, Molecular identification of an ABC transporter complex for manganese: analysis of a cyanobacterial mutant strain impaired in the photosynthetic oxygen evolution process, EMBO J., 1995, 14, 1845-1853.

180 M. R. Badger and G. D. Price, The role of carbonic anhydrase in photosynthesis, Annu. Rev. Plant Physiol. Plant Mol. Biol., 1994, 45, 369-392. 
181 M. S. Kimber and E. F. Pai, The active site architecture of Pisum sativum beta-carbonic anhydrase is a mirror image of that of alpha-carbonic anhydrases, EMBO J., 2000, 19, 1407-1418.

182 Y. Lu, D. A. Hall and R. L. Last, A small zinc finger thylakoid protein plays a role in maintenance of photosystem II in Arabidopsis thaliana, Plant Cell, 2011, 23, 1861-1875.

183 Y. Lu, The occurrence of a thylakoid-localized small zinc finger protein in land plants, Plant Signaling Behav., 2011, 6, 1881-1885.
184 D. G. Nocera, The Artificial Leaf, Acc. Chem. Res., 2012, 45, 767-776.

185 N. Rukhshi and I. Lee, Artificial Photosynthesis Now a Reality, The Berkeley Energy Review, 2012, http://ucs.berkeley. edu/energy/tag/artificial-leaf/.

186 D. C. Hong, Y. Yamada, T. Nagatomi, Y. Takai and S. Fukuzumi, Catalysis of Nickel Ferrite for Photocatalytic Water Oxidation Using $[\mathrm{Ru}(\mathrm{bpy})(3)](2+)$ and $\mathrm{S}_{2} \mathrm{O}_{8}{ }^{2-}, J$. Am. Chem. Soc., 2012, 134, 19572-19575. 